\title{
$\underline{\text { Real-time Tracer Monitoring of Reservoir Stimulation Procedures }}$ \\ $\underline{\text { Via Electronic Wireline and Telemetry Data Transmission }}$ \\ ANNUAL TECHNICAL PROGRESS REPORT
}

June 2002 - June 2003

\author{
Realtimezone- George Scott III \\ 100 N. Pennsylvania \\ Roswell, NM 88203
}

August 2003

DE-FC26-99FT40129

DISCLAIMER: This report was prepared as an account of work sponsored by an agency of the United States Government. Neither the United States Government nor any agency thereof, nor any of their employees, makes any warranty, expressed or implied, or assumes any legal liability or responsibility for the accuracy, completeness, or usefulness of any information, apparatus, product, or process disclosed, or represents that its use would not infringe privately owned rights. Reference herein to any specific commercial product, process, or service by trade name, trademark, manufacturer, or otherwise does not necessarily constitute or imply its endorsement, recommendation, or favoring by the United States Government or any agency thereof. The views and opinions of authors expressed herein do not necessarily state or reflect those of the United States Government or any agency thereof. 


\section{ABSTRACT: TECHNICAL PROGRESS REPORT}

Annual Report: June 2002 - June 2003

Realtimezone- George Scott III

DE-FC26-99FT40129

Ongoing Phase 2-3 work comprises the final development and field-testing of two complementary real-time reservoir technologies; a stimulation process and a tracer fracturing diagnostic system. Initial DE-FC26-99FT40129 project work included research, development, and testing of the patented gamma tracer fracturing diagnostic system. This process was field-proven to be technically useful in providing tracer measurement of fracture height while fracturing; however, technical licensing restrictions blocked Realtimezone from fully field-testing this real-time gamma diagnostic system, as originally planned. Said restrictions were encountered during Phase 2 field test work as result of licensing limitations and potential conflicts between service companies participating in project work, as related to their gamma tracer logging tool technology. Phase 3 work principally demonstrated field-testing of Realtimezone (RTZ) and NETL's Downhole-mixed Reservoir Stimulation process. Early on, the simplicity of and success of downhole-mixing was evident from well tests, which were made commercially productive. A downhole-mixed acid stimulation process was tested successfully and is currently commercially used in Canada. The fourth well test was aborted due to well bore conditions, and an alternate test project is scheduled April, 2004. Realtimezone continues to effectuate ongoing patent protection in the United States and foreign markets. In 2002, Realtimezone and the NETL licensed their United States patent to Halliburton Energy Services (HES). Additional licensing arrangements with other industry companies are anticipated in 2004-2005. Ongoing Phase 2 and Phase 3 fieldtesting continues to confirm applications of both real-time technologies. Technical data transfer to industry is ongoing via Internet tech-transfer and various industry presentations and publications including Society of Petroleum Engineers. These realtime enhanced stimulation procedures should significantly increase future petroleum well recoveries in the United States, onshore and offshore, and in vertical and horizontal wells. 


\section{TABLE OF CONTENTS}

Title Page

page 1

Abstract

page 2

Table of Contents

page 3

List of Figures

page 4

Introduction

page 5

Executive Summary

page 6

Experimental

pages 8

Results and Discussion

pages 14

Conclusion

page 20

Appendix

page 21

Scott-Covatch; United States Patent \#6,439,310

i

August, 2002

page 21

Scott-Covatch-Carrasco; Society of Petroleum Engineers

ii

Article \#77676, September, 2002

page 36 


\section{List of Figures}

FIGURE ONE- Real-time Reservoir Gamma Tracer Survey

Page $10 \quad$ of Reservoir Fracture Propagation

FIGURE TWO- $\quad$ AAPG Explorer Article

Page 11

FIGURE THREE- NGX McKee St. 1 well test data: Reservoir Tracer Survey

Page 12 (post-fracture) for Borate gel/N2 Downhole-mixed stimulation process

FIGURE FOUR- NGX Experimental St. \#1 Fracture Treatment Chart

Page 18 Borate gel/CO2 Downhole-mixed Reservoir Stimulation Treatment

FIGURE FIVE- $\quad$ Tracer Survey Log, -NGX Experimental St. \#1

Page 19 Downhole-mixed Reservoir Stimulation Treatment

Borate gel/CO2 Downhole-mixed Reservoir Stimulation Treatment 


\section{TECHNICAL PROGRESS REPORT}

\section{Annual Report: June 2002 - June 2003 \\ Realtimezone- George Scott III}

DE-FC26-99FT40129

\section{INTRODUCTION}

Realtimezone's Phase 2-3 ongoing work includes final field-testing of a real-time reservoir fracturing diagnostic system. Real-time fracture analysis has been accomplished by gamma tracer monitoring in experimental well tests. In addition, a novel real-time reservoir stimulation treating process has been successfully developed, which is henceforth referred to as the Downhole-mixed Reservoir Stimulation (DRS) process.

The DRS process was patented in 2002 by Realtimezone (RTZ) and the National Energy Technology Laboratory (NETL) in Canada, Brazil, Venezuela and the United States. This reservoir stimulation technology is currently licensed to a major U.S. energy service provider. Realtimezone continues to effectuate ongoing licensing protection in the United States with industry service providers, and foreign markets, to the benefits of RTZ and NETL. The considerable expense of this patent work, including foreign patents, is funded by Realtimezone and the project Principal Investigator.

The timelines for the various project tasks have been extended through June, 2004. This task work will further field-prove Realtimezone's technologies, which have potentially numerous applications for enhanced recovery of oil and natural gas reserves in the United States. DRS works efficiently in both onshore and offshore reservoirs, and in vertical and horizontal wells.

Since initial Phase 1 work that commenced in 1999, RTZ's Phase 2 research and field-test work has principally consisted of research and development of the real-time tracer diagnostic system for monitoring reservoir-fracturing geometry (fracture height). Phase 3 project work includes the development and testing of Realtimezone's downhole-mixed reservoir stimulation system along with final development testing of the tracer diagnostic system as illustrated in Figure 1.

To date, four well tests have been conducted. In all test well cases where test work was completed as planned, the downhole-mixed stimulation treatments were successful; oil or gas production increased to commercial levels in the test wells, except a fourth well test that was aborted due to well bore conditions. A fifth well test well project is scheduled for 2004.

Technical data transfer to industry is ongoing. RTZ made two major presentations in 2002 to the American Association of Petroleum Geologists (AAPG) in Ruidoso, New Mexico, and at a NETL Workshop in 
Denver, Colorado. An AAPG Explorer article discussing RTZ's project work is illustrated in Figure 2. Conceptual details of downhole-mixed reservoir stimulation procedures are further described in more specific details in United States patent (see Appendix i) issued in 2002. A major talk was given to the Society of Petroleum Engineers (SPE) in San Antonio, Texas, in October, 2002, along with a SPE symposium publication (Appendix ii). Talks have also been presented to numerous various oil companies, including Yates Petroleum and to petroleum engineering students and faculty at New Mexico Tech.

\section{EXECUTIVE SUMMARY}

(DE-FC26-99FT40129)

This research project comprises two major objectives: research and development of a real-time reservoir stimulation diagnostic system via electronic data transmission, and research and development of a real-time enhanced downhole-mixed stimulation process. To date, successful field tests by Realtimezone (RTZ) have proven various applications of both real-time technologies; gamma-traced fracture diagnostic system has been technically proven to help diagnose hydraulic fracture dynamics, including fracture height, in real-time and the downhole-mixed reservoir stimulation (DRS) processes have significantly improved petroleum production in Realtimezone's well tests. Presently the downhole-mixed stimulation process is the technology being most widely adapted by industry.

Realtimezone's gamma-traced fracture diagnostic system has been technically proven to help diagnose real-time hydraulic fracture dynamics, including fracture height, as the fracturing process is propagated. While at times nerve-racking during well tests, the only problem that was difficult to solve was due to the logistics involved in testing the gamma diagnostic logging system. These limitations developed after the service company initially providing the gamma logging tools for the well test work licensed said tools to another company, who then modified the logging devices. Halliburton Energy Services (HES) has been involved in field-testing, including well test tracer logging and stimulation work in their support of this project DE-FC2699FT40129 work. However, after the first year they licensed their wireline gamma radiation logging tools, which had been scheduled to be used in Realtimezone's well tests to monitor hydraulic fracturing tests. HES licensed all of their gamma logging wireline tools to ProTechnics, who has also supported RTZ-DOE NETL project test work by providing gamma tracer services. After ProTechnics acquired the HES logging tools, they converted them from wireline gamma logging tools into slickline, battery-operated memory tools, which compromised Realtimezone's further ability to monitor multiple tracers in real-time while fracturing. 
Experimental testing of the real-time diagnostic system was further complicated by the fact that HES wouldn't allow ProTechnics to run tracers on the low-pressure end of their pumping equipment, and ProTechnics, who didn't have a tagging system for high-pressure tagging, basically refused to work with the competitor tracer service company that performed high-pressure gamma tagging for well site tests. The net result was that realtime tracer measurement of hydraulic fracturing was field-demonstrated, however, several technical obstacles exist that may slow the widespread fruition of this reservoir diagnostic technology.

It is anticipated that final well test results from this year and next year should lead into commercialization of downhole-mixed reservoir stimulation processes. Downhole-mixing is an inherently safer procedure to pump that is characterized by lower treatment pressures. The lower treating pressures are principally a function of reduced fluid friction pressures. Substantially lower treating pressures are a significant factor wherever old tubulars, casing or pressure-restricted wellheads are present. In fact many conventional, surface-mixed stimulation treatments in the industry are prematurely terminated, due to excessive treating pressures.

Another advantage over existing conventional stimulation processes that is provided by downholemixing is the ability to modify and control fracturing treatments in real-time (on the fly). Real-time changes in fluid rheology and proppant concentrations occur at the well bore-fracture interface, which provides a serious advantage for well operators. These real-time changes are achieved by the mixing of fluids from both casing and tubing at or near the perforations, which allows common stimulation problems including "treating out of zone" to be prevented by minimally invasive fracturing. For example, one of the successfully stimulated test wells measured (via post-fracture tracer analysis) a minimum fracture height of less than 25 feet. In this same field area the majority of wells produce excessive water due to fracturing out of zone. The oil production from the downhole-mixed test well confirms the stimulation success. Project work includes experimental well testing of the efficacy of various downhole-mixed composite fluids. Well tests to date have demonstrated that admixtures of environmentally cleaner borate gel and either $\mathrm{CO}_{2}$ and/or $\mathrm{N}_{2}$ are easily propagated by downholemixing. This process works efficiently for fracturing either high or low-permeability reservoirs.

A fourth test well, the NGX Boggs Fee\#1 commenced in June, 2003. This Boggs Fee \#1 test well encountered unforeseen factors including numerous holes in intermediate casing due to $\mathrm{H}_{2} \mathrm{~S}$ gas, and deeper hole reentry problems, which have prevented the test work from being completed as planned. As a result of the unforeseen factors this test well was significantly over original planned budget. Another test well is planned in March, 2004.

Realtimezone-NETL's field-testing and further refinement of the real-time optimized reservoir stimulation processes will provide the petroleum industry enhanced reservoir stimulation capabilities. This 
stimulation technology should lead to increased production of reserves from numerous fields throughout the United States and foreign basins, both onshore and offshore, and in vertical and horizontal wells. These novel processes will be further field tested later this year, and in 2004.

\section{EXPERIMENTAL}

\section{DISCUSSION of METHODS \& PROCEDURAL PROCESSES}

Downhole mixing is accomplished by precision blending of gases, proppant, and fluids in the downhole region of the well, above or near the reservoir objective. This approach can eliminate the need for the greater pumping horsepower that is typically required under the higher friction pressures characteristic of viscous, surface-mixed stimulation fluids. Significantly lowered treating pressures are often critical to successfully fracturing reservoirs, particularly in deep wells that have a lot of friction pressure associated with pumping down small tubulars. This is especially true when treating wells in which old or weak tubulars are present, where pumping down the casing at high pressures or rates is not an option. When mechanical or safety issues are considered, downhole mixing is generally preferable to conventional stimulation methods.

Downhole blending occurs when different fluids for admixture are dual-injected through coiled or conventional tubing and the casing annulus near the reservoir zone. Thus, a composite fracturing fluid is created downhole before injection into the reservoir formation fracture. The aqueous-based fracturing fluid may be incorporated into either or both of the gases at the surface and may include proppant and other chemical components, which form the composite fracturing fluid upon mixing downhole. First, this fracturing fluid is blended downhole to avoid excessive friction pressures, and then it is injected at a viscosity and pressure sufficient to implement hydraulic fracturing of the selected reservoir interval.

Additives, including gelling agents, may be incorporated into the base fluid to increase fluid viscosity and improve proppant suspension, leak-off, and related rheological properties. $\mathrm{CO}_{2}$ may be provided in liquid phase through the tubing, and $\mathrm{N}_{2}$ may be provided in gaseous phase through the casing, or the $\mathrm{CO}_{2}$ may be injected down the casing and $\mathrm{N}_{2}$ down the tubing. The propping agent should be thoroughly mixed with the composite stimulation fluid immediately above or adjacent to the reservoir interval where the induced reservoir fracture or fractures are propagated.

Phase 2 work commenced with the design of a downhole injector tool and field-testing in reentered wells that for the most part were chosen for their availability as either dry wells or marginal stripper producers. Phase 2 and Phase 3 work also included preparing New Mexico Oil \& Gas Conservation environmental compliance forms related to well projects including establishing plugging bonds, liability insurance and related 
contracts for the test wells that contract operated by NGX, for Realtimezone. The ongoing development of intellectual property by Realtimezone will continue through at least June 2004. Realtimezone and the National Energy Technology Laboratory (NETL), as patent royalty owners under U.S. Patent \# 6,439,310, should potentially benefit from a recent License Agreement with Halliburton Energy Services (HES). Further Intellectual property work includes procedural reviews by P.I. and patent attorneys of the foreign patent applications in Venezuela, Brazil, and Canada.

Realtimezone's Internet web site further presents the downhole-mixed technology (www.realtimezone.net) and is currently updated with field-test data and results.

To summarize well test results to date, the first field-test well, the NGX Experimental St. \#1., confirmed that successful real-time stimulation processes are possible using downhole-blended fluids and gas. RealtimeZone reentered and successfully field-tested the novel patent-pending real-time stimulation process using downhole-blended $\mathrm{CO}_{2}$ and borate gel, with 20-40 proppant and methanol. This experimental well fracturing treatment was tagged with multiple isotopes for post-fracture measurement of fracture height and to delineate proppant placement within the 12,300 feet tight gas sandstone reservoir. The tracer survey log (see Figure Five) confirmed that the treatment was successfully pumped and adequate proppant placement was achieved within the targeted reservoir zone. Subsequent production results of approximately 250 MCFGPD further confirmed that this treatment worked as this well became commercially productive. The treating pressure chart (see Figure Four) illustrates that treating pressures remained significantly lower than would normally be encountered with conventional surface-mixed fracturing processes.

The second test well, the NGX McKee St. \#1, was chosen to test a dual-fluid downhole-mixed fracturing system using cross-linked oil and $\mathrm{CO}_{2}$. The design objective was to fracture stimulate the test well at significantly lower treating pressures than would be normally experienced by conventional fracturing methods. Another objective was to attempt to control the distribution of proppant in the reservoir, in real-time, by minimizing fracture height. The stimulation test included the use of downhole-mixing to activate the proppant's resin-coating, at the end of the stimulation test, to prevent proppant erosion and backflow into the well bore. Avoidance of produced proppant typically is desirable to save the life of downhole pumps and prevent equipment wear. 
FIGURE ONE- Real-time tracer log below illustrates the movement of gamma-tagged fluid and proppant in the fractured reservoir. Log data measurement occurred as the stimulation treatment was pumped.

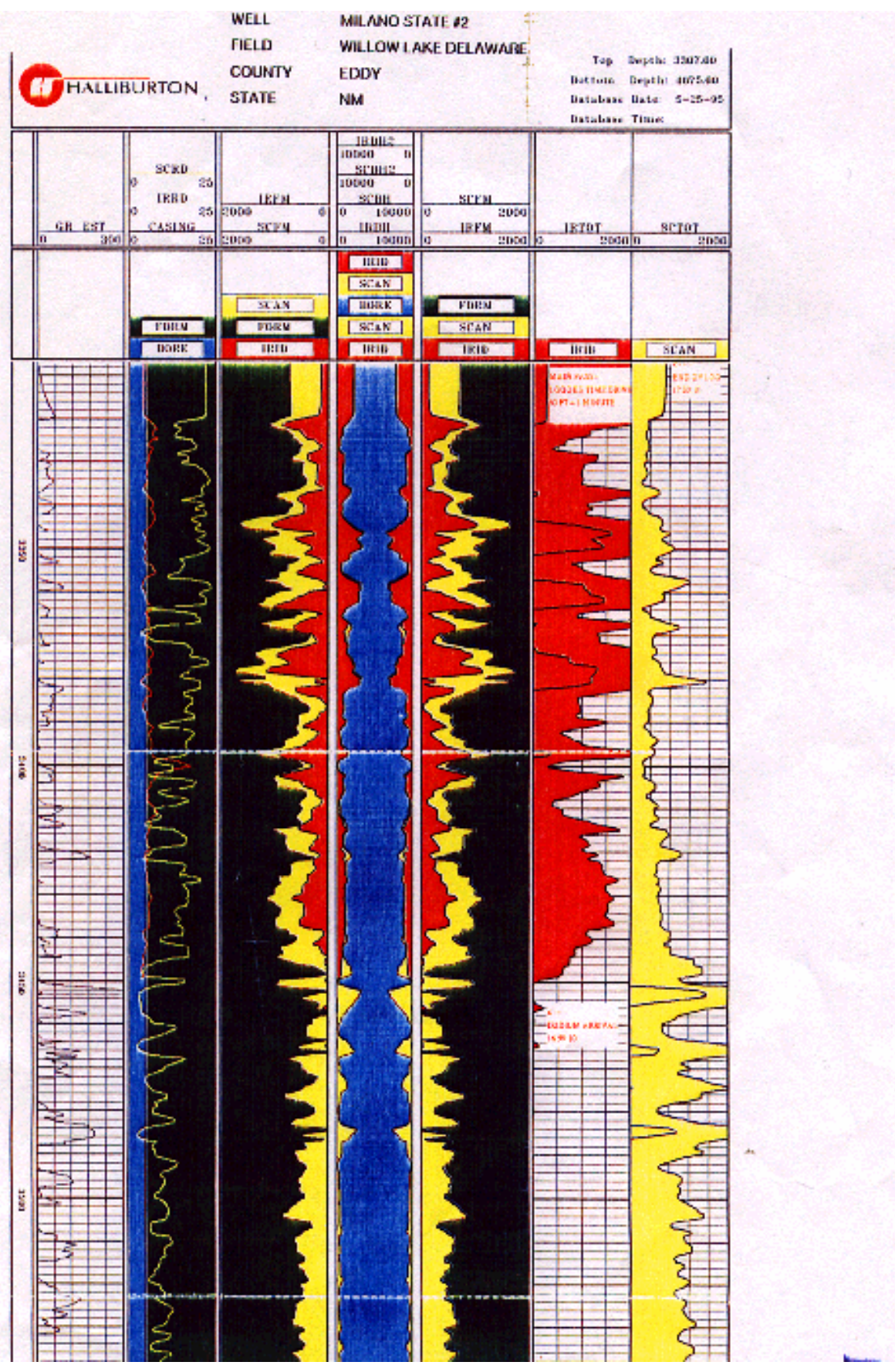




\section{FIGURE TWO: AAPG EXPLORER ARTICLE RE REALTIMEZONE}

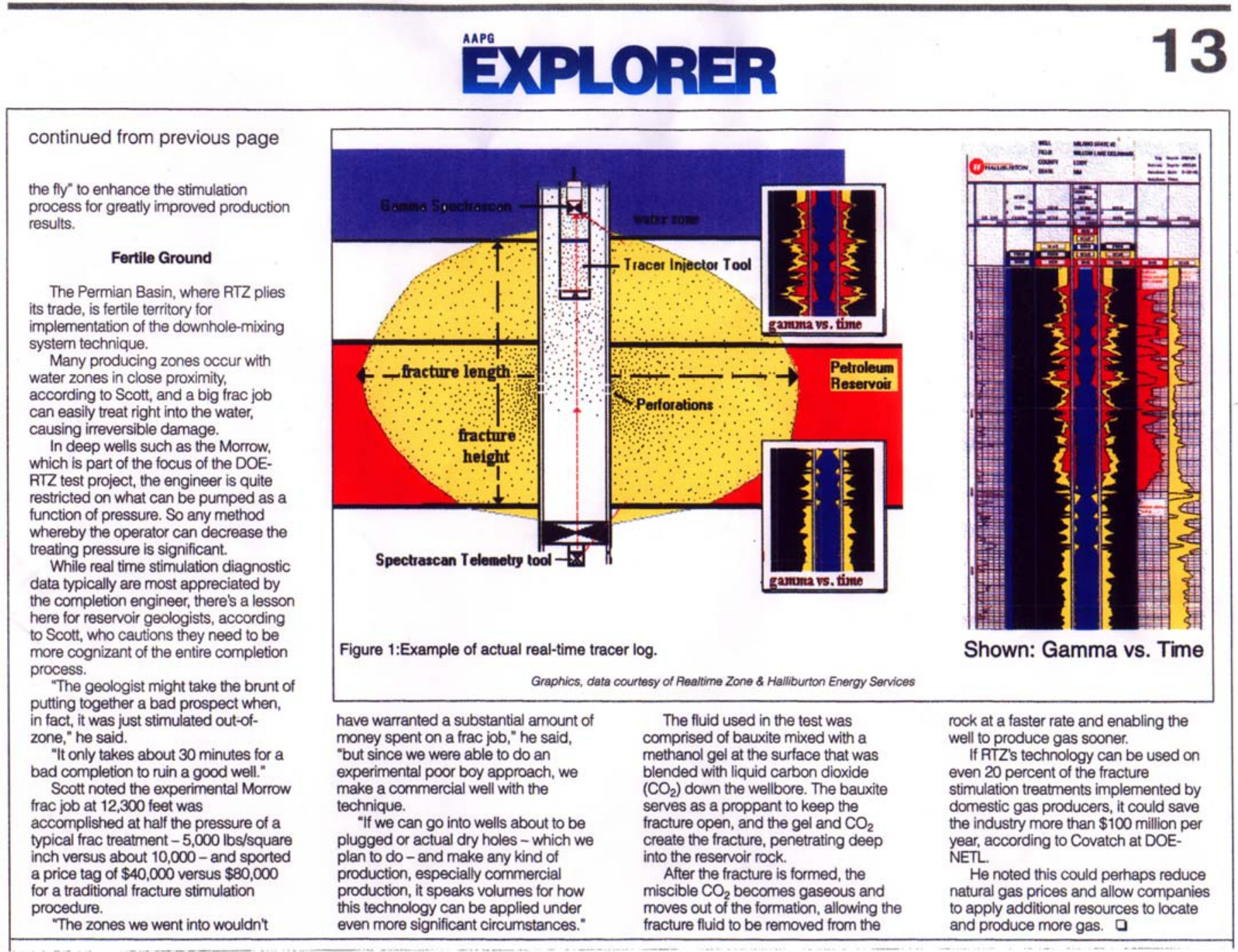

The results confirm (see Figure Three) that real-time downhole-mixed stimulation fluids (and proppant) may be ratio mixed to control specific qualities of fracturing slurry rheology for minimal fracture height growth, while also reducing surface treating and pipe friction pressures. During treatment in this $2^{\text {nd }}$ test well project, gelled lease oil fluid with proppant and $\mathrm{CO}_{2}$ were downhole-mixed to create a $50 \%$ foam fracturing treatment. Exhibit Four illustrates the placement of tracer in the fractured reservoir interval. The McKee St. \#1 treatment stayed in zone well according to post-fracture gamma tracer log. The well produced 8 BOPD, which was considered a technical success, however a second downhole-mixed stimulation treatment was pumped to test the efficacy of a downhole-mixed $\mathrm{N}_{2}$-borate gel system using borate gel, proppant and nitrogen, which resulted in a production increase to a steady 18 BOPD. 
FIGURE Three: Gamma tracer survey log showing downhole-mixed fracturing treatment pumped in Delaware oil reservoir at 5,100 feet. This Borate gel \& Nitrogen mixed frac job successfully treated in pay zone and avoided water-productive zones below.

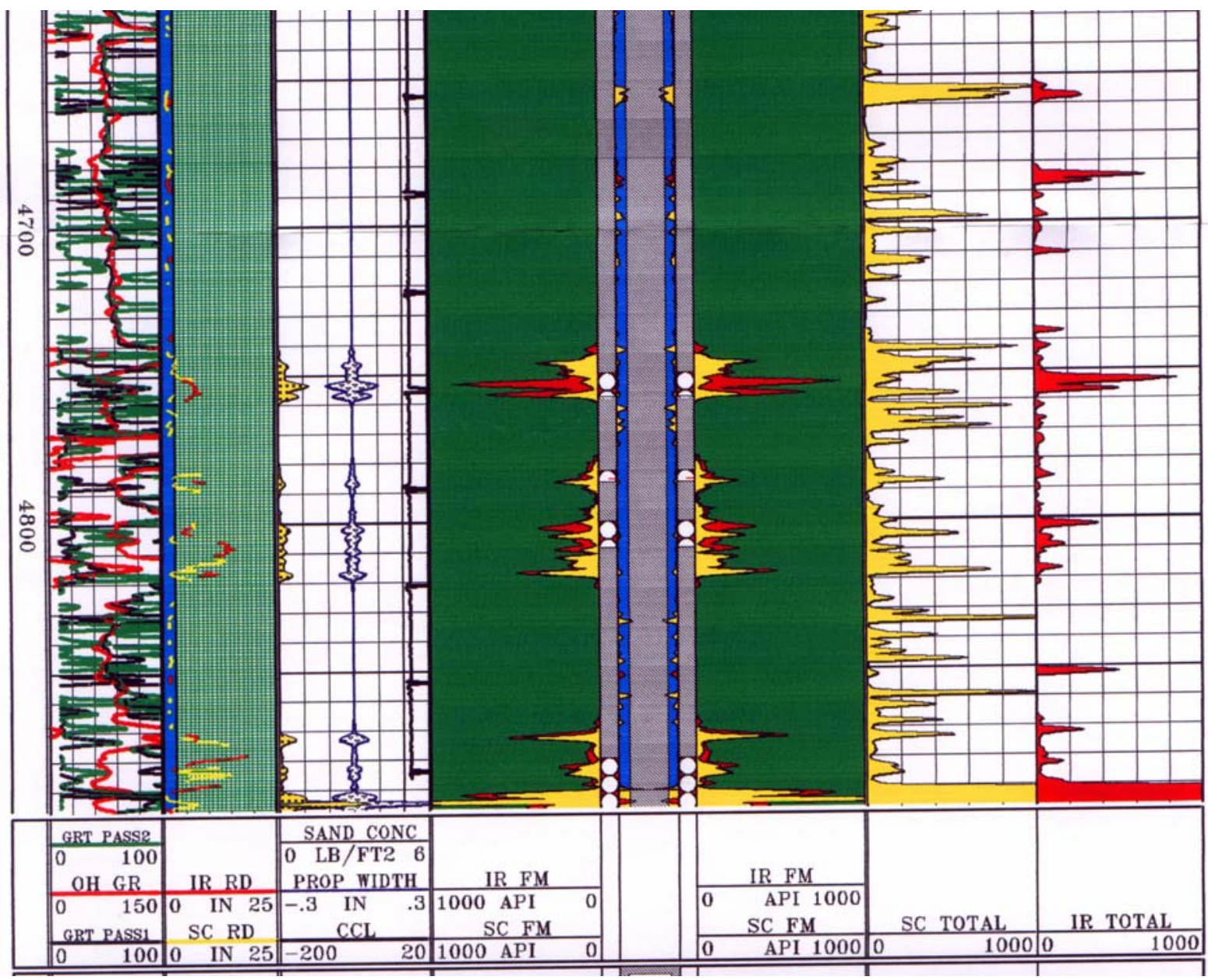

Downhole-blending of gases, including Nitrogen and methanol-gel, result in a composite stimulation fluid that is comparable in efficiency and proppant transport to a surface-mixed, energized foam treatment. However, there are numerous advantages observed with downhole-blended gas-gel composite fluids including lower fluid-pipe friction, lower pressures and reduced pump horsepower requirements. In addition, downholeblended stimulation treatments will alleviate chronic stimulation problems including premature screenout, fluidreservoir skin damage, excessive treating pressures, fracturing out of zone, and excessive water production.

The costs of dual-fluid well stimulation procedures would also be lower, due to reduced horsepower pumping requirements, and because less surface equipment is required. This simple, downhole-mixed 
completion technology thus easily enables the well operator to realize dramatic improvements in efficiency, safety, cost savings, and reservoir fracturing success.

The downhole-mixed fracturing fluid is blended downhole to avoid excessive friction pressures that otherwise result when fluids are mixed and thickened at the surface. A composite fracturing fluid is thus created downhole prior to injection into the reservoir formation fracture. An unfortunately common characteristic of such "tight" (low-permeability) gas-bearing sandstones at this depth is that a comparatively high pressure fracturing treatment is required. As a result, typically special tubing and casing designs are required due to excessive treating pressures, which are observed when fracturing at this depth. Often deeper reservoirs are not successfully fractured by present industry techniques, typically due to excessive treating pressures. As a result, substantial petroleum and particularly natural gas reserves are inefficiently stimulated. This chronic loss of reserve value is widespread in the petroleum industry. Particularly in the absence of natural reservoir fractures, virtually all low-permeability natural gas reservoirs require an adequate fracturing treatment to improve flow from the reservoir to the well bore and surface. The stimulated recovery of natural gas from tight reservoirs is directly a function of obtaining both adequate length of induced fracture propagation and sufficient proppant placement therein.

Known additives, including thickening agents, may be incorporated into the base-fluid to increase fluid viscosity, to improve proppant suspension, leak-off and to effectuate desirable rheological properties. Thorough mixing of the propping agent with the composite stimulation fluid preferably occurs immediately above or adjacent to the targeted reservoir interval where the induced reservoir fracture or fractures are propagated. A variety of problems are avoided in real-time by the simple method of downhole mixing, which provides the ability to instantaneously modify stimulation treatments by rapid changes in pump rate, fluid rheology and proppant concentrations. This inventive system typically minimizes friction pressures and thus provides lower treating pressures and higher pumping and injection rates.

By providing separate conduits for respective separate fluid compositions at the surface, composite downhole fracturing fluid combinations that might otherwise have been impractical if mixed at the surface, may be permissible. For example, a first fracturing fluid phase including carbon dioxide may be pumped down the tubing, while a second fluid phase including nitrogen, gelled aqueous fluid and proppant may be pumped down the casing annulus. The first and second fluid phases may combine and mix downhole in the casing to form a composite fracturing fluid that might otherwise have exhibited too much friction loss to have been pumped from the surface as a composite fracturing fluid.

Additional field-testing of the downhole-mixed process is scheduled to commence later this year with the re-entry and completion of the NGX Boggs Fee\# 1. This next scheduled well test will also include a real- 
time tracer monitored fracturing treatment. Present plans are to monitor in both upward and downward vertical directions with respect to the targeted reservoir.

\section{RESULTS AND DISCUSSION}

A significant portion of this project work has been successfully conducted in three field test results obtained to date from the NGX Experimental St. \#1 and NGX McKee St. \#1 wells. A fourth field test is scheduled prior to year-end in the NGX Boggs Fee \#1.

The ongoing development of a real-time tracer diagnostic system remains technically feasible, however, several logistical problem were encountered in the course of field test work. One problem was due to the fact that HES had just previously licensed their gamma logging tools to Corelab's ProTechnics for conversion and use in battery-powered slickline operations. As a result, the future availability of HES's wireline tools is very limited. Another complication has resulted from the fact that as a tracer provider, ProTechnics is not allowed to run their tracers through HES's smaller pump trucks. HES allows only high-pressure tagging operations, which are only available through the services of another tracer provider, Cardinal Survey. However, ProTechnics refuses to use their tracers or gamma detector equipment with Cardinal (their competitor). And Cardinal has only a single gamma detector source. As a result, Realtimezone has been forced to use Cardinal for both tracer and wireline gamma detector services, which precludes use of ProTechnics's multiple spectra gamma detector memory tool, as previously planned.

The results of ongoing research and development have led to numerous breakthrough concepts related to both the tracer diagnostic system and downhole-mixed fracturing process. Downhole-mixing concepts in particular have been developed that should simplify and revolutionize the present industry stimulation processes that are used for reservoir stimulation. It is anticipated that the final scheduled well test work will confirm many of these novel concepts. Excepting crew and equipment-license use limitations, field-testing operations to date have been conducted smoothly and without problems or unexpected circumstances. Field data acquisition and the results of experimental well testing were generally very successful.

The advantages of the downhole-mixed system are numerous in comparison to existing surface-mixed reservoir stimulation procedures, which are generally inflexible, whereas downhole mixing allows easy adjustment of treatment design while the fracture treatment is mixed downhole. Downhole-mixing also typically minimizes friction pressures, providing lower treating pressures and higher pumping and injection rates. This real-time fracturing process can minimize and potentially eliminate many common industry stimulation problems, including fluid-reservoir skin damage, excessive treating pressures, fracturing out of zone, and 
excessive water production. These problems can result in a significant loss of hydrocarbon reserves and severe economic loss to the operator.

Downhole-mixing also provides numerous options for real-time modification of fluid rheology and proppant concentration, and maximizing proppant placement while minimizing the common stimulation problems that can result in poor recovery efficiency. With downhole mixing, stimulation treatments can be instantaneously modified with rapid changes in pump rate, fluid rheology, and proppant concentrations. Altering the rates at which the tubing and casing components are pumped can control the net composition of the composite fracturing fluid (i.e., rheologic properties) and proppant concentrations. For example, increasing the volumetric rate of $\mathrm{CO}_{2}$ pumped down the tubing can change the composite fracturing fluid, in real time, from a ratio of $40 \% \mathrm{CO}_{2}$ to $30 \% \mathrm{~N}_{2}$ to $30 \%$ aqueous fluid slurry (with proppant) to a $70 \% \mathrm{CO}_{2}$ to $15 \% \mathrm{~N}_{2}$ to $15 \%$ aqueous fluid slurry. Although the pumping equipment is located at the surface, the effectuated increase in tubing pump rate is immediately evidenced at the bottom of the wellbore and results in a real-time change in the composite fracturing fluid entering the formation. The rate of change may be further accentuated by simultaneously decreasing the casing annular pump rate while increasing the tubing pump rate, such as might be indicated by premature screenout and the need to radically reduce proppant entry into the formation.

Existing completion systems use surface-mixing of the composite fracturing fluid. The pressures required to pump such stimulation treatments are relatively high, particularly during the injection of gelled, thickened fluids required to carry proppant into the fractures. Often, these pressures may become excessive during the treatment process, and the operator must prematurely terminate the treatment before serious equipment damage or safety problems occur.

Another significant problem associated with surface-blended composite fluids is that inhibitors are required to delay the crosslinking of the stimulation fluid before pumping downhole. Typically crosslinking occurs in the lower region of the wellbore before the fluid enters the perforated formation. Highly viscous gels effectively transport the proppant, but if premature viscous gelling occurs in the tanks and flowlines or before the fluid is pumped down the well, higher pressures and lower pump rates can occur, compromising the efficiency of the overall stimulation job. Inhibitors and other additives can be mixed into the composite fluid mixture at the surface to provide a controlled, time-delayed gelling of the composite fracturing fluid. A serious shortcoming of this surface-mixed approach, however, is that inadequate gel quality frequently results in poor proppant transport and premature screenout. Downhole blending of fluids can reduce or eliminate this timing factor, assuring a more uniform gel quality. Otherwise impractical composite downhole fracturing-fluid combinations mixed at the surface may be permissible if a conduit for each fluid composition is provided at the surface. For example, a first fracturing-fluid phase including $\mathrm{CO}_{2}$ may be pumped down the tubing, while a 
second fluid phase including $\mathrm{N}_{2}$, gelled aqueous fluid, and proppant may be pumped down the casing annulus. The first and second fluid phases can mix downhole in the casing and form a composite fracturing fluid that otherwise might have exhibited too much viscosity to be pumped from the surface as a composite fracturing fluid. Similarly, crosslinking may be performed downhole in the casing without relying on delayed crosslinking techniques that result from less predictable fluid $\mathrm{pH}$ changes.

Although mixing along the interfaces of the different density phases may occur, the vertical separation of discrete phases in the fractures, due to fluid phase or density variations, may likely result. Under some circumstances, this discrete separation of phase types in the fracture is desirable because separation can help avoid placement of proppant in water-productive zones, and fracturing into gas-oil, gas-water, or water-oil contacts in the reservoir.

In fact, sometimes treatments can damage, rather than enhance, reservoir productivity, and reserves and revenues are lost. An unsuccessful treatment may result from incompatible fluids and poor fluid recovery after fracturing because low-permeability reservoirs do not effectively flow back fluids from the matrix pores effectively (compared to higher-permeability reservoirs). This lack of efficient fluid cleanup is typically evidenced by fluid-mineral interaction (skin damage) and substantially reduced fluid entry into the wellbore. Unsuccessful fracturing treatments may also result from inefficient placement of sand proppant in the induced reservoir fracture or excessive water production from fracturing vertically away from the reservoir interval (and into water-bearing strata). This type of treating out of zone can result in economic losses and lost petroleum reserves. In addition, extensive well stimulation costs are wasted.

Although a well that has been fractured out of zone can sometimes be saved, remedial efforts are often extensive, risky, and costly. The proposed dual-fluid fracturing system tests can provide a valuable solution to these problems by providing simpler and more effective methods that may include a more focused method of fracturing. In many fields, this system can control fracture propagation during stimulation and help prevent chronic problems and minimize water production that can occur when a well is fractured out of zone.

In addition to fracture stimulation procedures, downhole mixing also has remediation applications. For example, precision blending of sodium silicate polymers and chemical activators can help efficiently induce plugging of water-productive zones (before, after, or during fracturing). Another example is resin-coated proppants that may be selectively activated downhole. Additional testing is needed to develop a full spectrum of real-time and dual-fluid stimulation and remediation processes.

In other cases, fracturing treatments are terminated prematurely or reduced in size because the excessive pumping pressures create the potential of exceeding the rated casing or tubing burst pressure. In deeper wells, surface wellhead treating pressures can approach 10,000 psi or higher. Conversely, bottomhole treating 
pressures at the reservoir formation depth are significantly higher due to the combination of the hydrostatic weight of the composite fracturing fluid (in wellbore) and surface pumping pressures and friction pressure. The resultant bottomhole treating pressures, if excessive, may crush or fracture proppants in the fracture, which can cause fines release, fracture closure, and formation damage. Higher treating pressures also require lower pump rates, which can alter the overall fracturing stimulation design at the wellsite. Frequently, job designs are dictated by pump rates. Typically, higher pumping pressures result in larger horsepower requirements, the usage of more pump engines, and higher cost. Downhole mixing can help alleviate these common industry problems.

\section{Field Tests}

The first dual-fluid fracturing treatment was blended downhole at approximately $12,300 \mathrm{ft}$ in a deep gas reservoir (Pennsylvanian Morrow formation). FIGURE FOUR illustrates the pumping pressures of tubing and casing during the experimental fracturing treatment. Pressures were 4,000 psi lower than average treating pressures for this depth.

The post-fracture tracer log (FIGURE FIVE) shows that the dual-fluid fracturing treatment successfully placed 7,000 $\mathrm{lb}$ of proppant into the induced reservoir fracture at 12,300 $\mathrm{ft}$. A commercial gas producer (approximately 5,000 Mcf per month) was created from a wellbore that was scheduled for plugging.

The tracer survey log (FIGURE FIVE) and produced oil cut confirmed that adjacent water intervals were not treated. The measured minimum fracture height was less than $40 \mathrm{ft}$ and the majority of the treatment was concentrated within $25 \mathrm{ft}$ of the reservoir section. This low fracture height is especially significant because relatively low fracture gradients usually occur in the general field area. Most shallow wells in this field area exhibit fracture heights in the range of 100 to $300 \mathrm{ft}$. The field wells that are treated out of zone are typically characterized by excessive water production.

The second dual-fluid fracturing treatment was downhole-blended at 4,900 $\mathrm{ft}$ in a shallow oil reservoir (Permian Delaware formation). Other oil wells in this field area are typically characterized by excessive water production resulting from treatment out of zone. The pressure treatment chart (FIGURE THREE) shows that the reservoir interval in this test well was successfully stimulated by placement of 7,470 $\mathrm{lb}$ of proppant at $4,900 \mathrm{ft}$, with screenout selectively induced in the fracture near the end of the treatment. Oil production from this well increased $300 \%$ with no increase in water production. 


\section{FIGURE FOUR - NGX Experimental St. \#1 Fracture Treatment Chart}

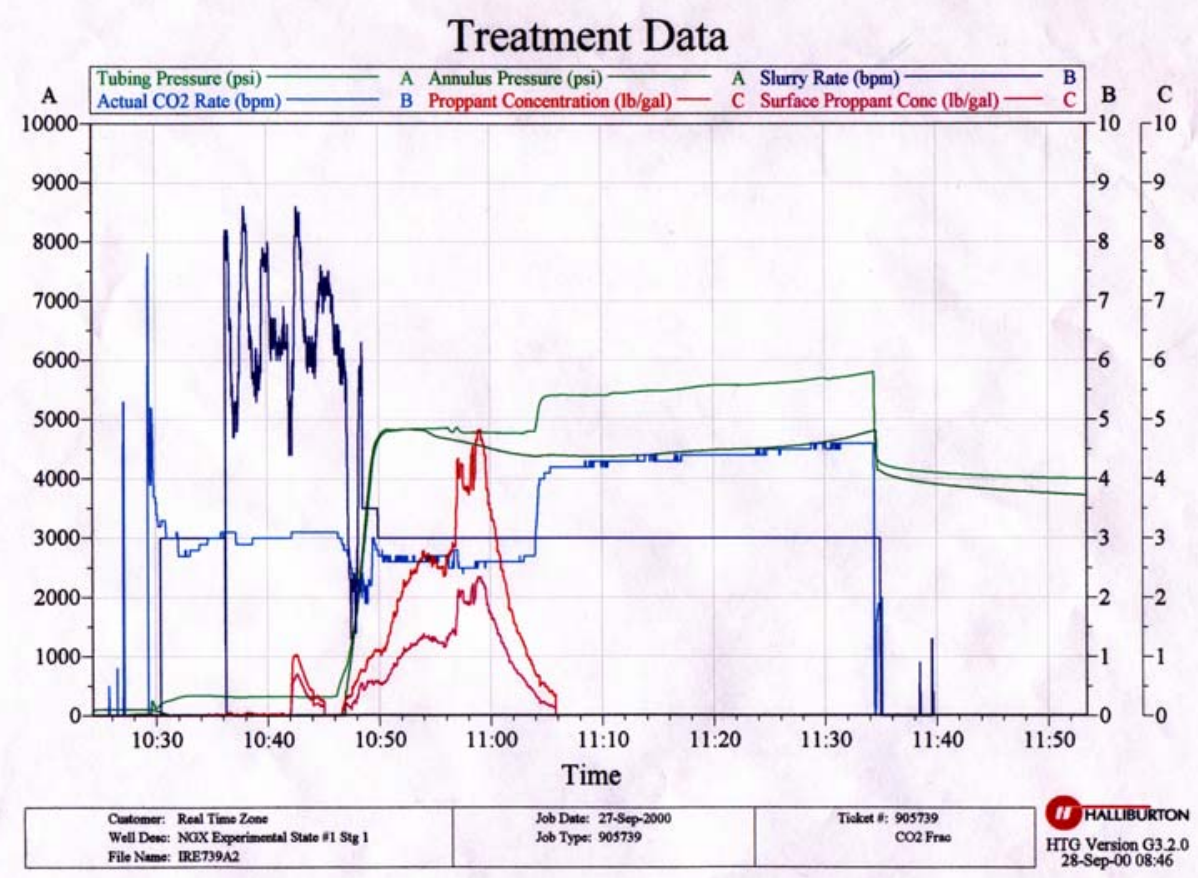

Completed field tests have proven that the process is technically feasible. Further testing will also help finalize algorithms related to dual-fluid field pumping procedures. The scientific significance includes the fact that friction pressures between fluids, casing, and tubing are reduced. Further field confirmation of the dynamic downhole-mixing processes should aid in determining applications for this method and result in the widespread adaptation over current stimulation methods.

Downhole mixing facilitates instant modification of the fracture treatment, and provides near instantaneous alteration of fluid viscosity and proppant concentrations at the reservoir, in real-time. At this juncture, several additional "smart frac" processes still need to be tested. Further modeling and field-testing will assure that this technology and valuable variations of the real-time dual-fluid stimulation system become utilized on a widespread basis by industry. Developing and demonstrating the various applications of this proprietary technology, via well tests, will benefit the petroleum industry and domestic consumers alike throughout the United States. 
FIGURE FIVE- Tracer Survey Log, -NGX Experimental St. \#1

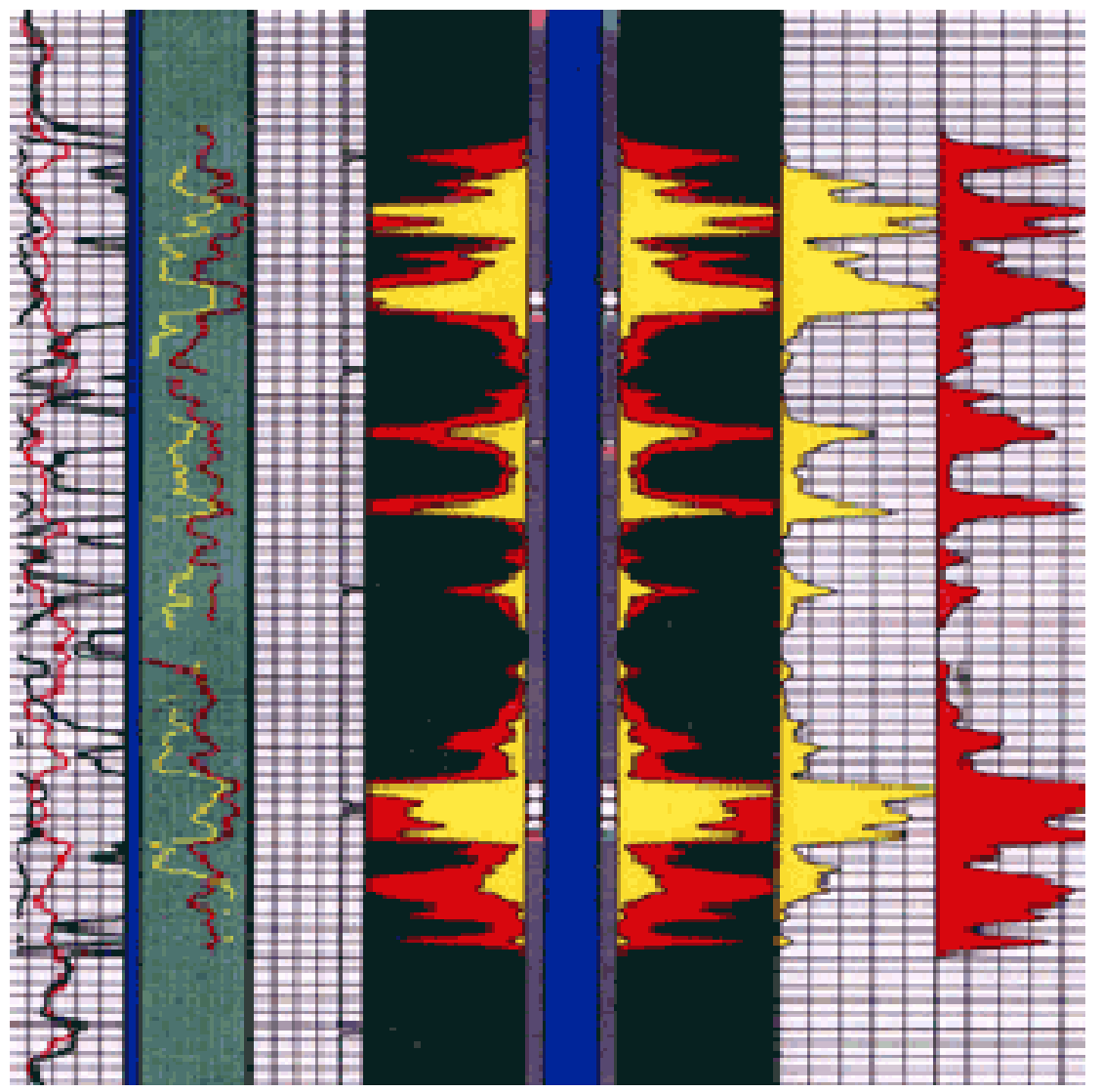

In recent years, downhole-mixed acid stimulation treatments have reportedly been pumped in the U.S. and Canada. However, no royalty funds have been received yet from service companies to either RTZ or NETL. Realtimezone and P.I. will continue to investigate the status of alleged unpaid royalties from our downhole-mixed stimulation procedures. Furthermore, if it is in fact determined that our patented processes were pumped without remediation, Realtimezone may seek legal options including remedies to protect intellectual property rights that are covered under U.S. Patent \#6,439,310. Ideally all service companies may be licensed under this technology subject to mutually agreeable terms that include royalty payments to RTZ and NETL. 


\section{CONCLUSION}

Downhole-mixed fracturing technology provides an enhanced stimulation process that can directly improve the recovery of petroleum reserves. Advantages of downhole mixing include economy, efficiency, and safety. The costs of downhole mixing are comparatively less than normal industry fracturing procedures because downhole mixing requires lower friction pressures, which translates into reduced fuel and pump horsepower requirements. The lower observed treating pressures that result help prevent accidents and equipment damage.

Downhole-mixing can provide well operators the ability to instantly modify fracturing treatment mixture and proppant concentrations at the reservoir, resulting in increased reservoir recovery efficiency. Downhole mixing can be used to blend different fracturing fluid phases and induce viscosity interfingering in the reservoir fracture. This real-time enhanced process facilitates control of fracture height and allows the stimulation treatment and proppant placement to be concentrated in the desired reservoir interval, directly resulting in the increased recovery of petroleum reserves.

The process of downhole-mixed fracturing is simpler, safer and lower cost than typical surface-mixed stimulation treatments. In addition, this enhanced stimulation procedure provides the well operator a real-time process to control proppant concentration and placement in the reservoir, enhancing the recovery of petroleum reserves. Ultimately, the widespread application of this enhanced stimulation technology could result in more efficient and more substantial recovery of natural gas and oil.

Introduction of the dual-fluid system to the industry requires additional field-testing to demonstrate more applications in various types of reservoirs, including low-permeability gas zones. Dissemination of test result data to the petroleum industry is crucial to the development of a more full-spectrum dual-fluid fracturing system. The innovative dual-fluid fracturing system is simple to use at the wellsite and advantages include economy, efficacy, and safety.

The upcoming scheduled project well test work will facilitate further development of this novel system. 


\title{
Appendix
}

United States Patent

$6,439,310$

George Scott, III and Gary Covatch

August 27, 2002

\section{Real-time reservoir fracturing process}

\begin{abstract}
Methods are disclosed for hydraulic fracturing of subterranean reservoir formations using various combinations of gelled fluid, nitrogen, and carbon dioxide base components, in association with proppant and other additives. Selected base components are pumped down a wellbore tubing while other selected base components are simultaneously pumped down the wellbore tubing-casing annulus for downhole mixing into a composite fracturing fluid in the downhole region of the wellbore proximal to the reservoir objective. Thereby, changes may be timely effected in the composite fluid composition and fluid properties, substantially immediately prior to the composite fluid entering the formation. Such real-time modifications may be effected to readily preempt screenout occurrences and may facilitate composite fluid compositions which otherwise are frequently undesirable to pump from the surface. Such composite fluid combinations include components phases of each of carbon dioxide, nitrogen and a base fluid. Proppant concentrations within the composite fluid entering the formation may be effected in real time without the wellbore-volume lag-time inherent in prior art methods.
\end{abstract}

Inventors: Scott, III; George L. (100 N. Penn, Roswell, NM 88201); Covatch; Gary L. (220 Canyan Village, Morgantown, WV 26508)

Appl. No.: 844951

Filed: $\quad$ April 27, 2001 
Current U.S. Class:

Intern'l Class:

Field of Search:
166/308.1; 166/250.1; 166/250.12

E21B 043/26

$166 / 308,250.1,250.12$

\section{References Cited [Referenced By]}

\begin{tabular}{|c|c|c|c|}
\hline \multicolumn{4}{|c|}{ U.S. Patent Documents } \\
\hline$\underline{2869642}$ & Jan., 1959 & McKay et al. & $166 / 250$ \\
\hline$\underline{2947869}$ & Aug., 1960 & Egan et al. & $376 / 167$ \\
\hline$\underline{3602308}$ & Aug., 1971 & Vincent & $166 / 281$ \\
\hline 4228885 & Oct., 1980 & Cavalleri & 194/242. \\
\hline$\underline{4627495}$ & Dec., 1986 & Harris et al. & $166 / 280$ \\
\hline$\underline{5069283}$ & Dec., 1991 & Mack. & \\
\hline$\underline{5595245}$ & Jan., 1997 & Scott, III. & \\
\hline$\underline{5635712}$ & Jun., 1997 & Scott, III et al. & \\
\hline \multicolumn{4}{|c|}{ Primary Examiner: Dang; Hoang } \\
\hline \multicolumn{4}{|c|}{ Attorney, Agent or Firm: Helmreich; Loren G. Browning Bushman } \\
\hline \multicolumn{4}{|c|}{ Parent Case Text } \\
\hline \multicolumn{4}{|c|}{ This application claims priority from U.S. provisional application 60/232,717 filed Sep. 15, 2000.} \\
\hline \multicolumn{4}{|c|}{$\begin{array}{l}\text { The invention described herein in part was made in the performance of work supported by the U.S. Department } \\
\text { of Energy. Thereby, the U.S. Government has certain rights in the invention. }\end{array}$} \\
\hline
\end{tabular}




\section{Claims}

What is claimed:

1. A method of hydraulically fracturing a subterranean formation penetrated by a wellbore, at least a portion of the wellbore including a tubing string having a tubing bore and a casing string, the casing string and tubing string forming a casing annulus, a portion of the well bore not including the tubing string therein forming a casing bore, the method comprising:

injecting carbon dioxide into the wellbore via one of the tubing bore and the casing annulus at a first injection flow rate;

simultaneously injecting nitrogen into the wellbore via the other of the tubing string and casing annulus at a second injection flow rate;

simultaneously injecting an aqueous fracturing fluid into the wellbore with at least one of the carbon dioxide and nitrogen, at a third injection flow rate;

combining the carbon dioxide, the nitrogen and the aqueous fracturing fluid in the casing bore to form a downhole mixed composite fracturing fluid having a mixed fluid composition;

injecting the downhole mixed composite fracturing fluid from the casing bore into the subterranean formation at a hydraulic pressure sufficient to hydraulically fracture the formation; and

selectively varying one or more of the first injection flow rate, the second injection flow rate, and the third injection flow rate to modify in real time the mixed fluid composition of the downhole mixed composite fracturing fluid, forming a modified downhole mixed composite fracturing fluid.

2. The method as defined in claim 1, further comprising:

adding a solid material proppant to the aqueous fracturing fluid to form a proppant laden downhole mixed composite fracturing fluid having another mixed fluid composition; and

thereafter injecting the proppant laden downhole mixed composite fracturing fluid from the casing bore into the subterranean formation at hydraulic pressures sufficient to hydraulically fracture the formation.

3. The method as defined in claim 2, further comprising:

selectively varying one or more of the first injection flow rate, the second injection flow rate, and the third injection flow rate to modify in real time the another mixed fluid composition of the proppant laden downhole mixed composite fracturing fluid.

4. The method as defined in claim 2, wherein a quantity of proppant in the proppant laden downhole mixed composite fracturing fluid is selectively adjusted in real time by varying at least one of the first injection flow 
rate, the second injection flow rate, and the third injection flow rate.

5. The method as defined in claim 2, further comprising:

monitoring in real time within the well bore a location in the formation of at least one radioactive tracer provided in at least a portion of one or more of the downhole mixed composite fracturing fluid and the proppant laden downhole mixed composite fracturing fluid by monitoring radioactive emissions from the at least one radioactive tracer; and

varying at least one of the first injection flow rate, the second injection flow rate, and the third injection flow rate in response to the monitored radioactive emissions.

6. The method as defined in claim 1, further comprising:

while selectively varying one or more of the first injection flow rate, the second injection flow rate and the third injection flow rate, increasing a viscosity of the modified downhole mixed composite fracturing fluid as compared to the downhole mixed composite fracturing fluid and cause viscous inter-fingering of the modified downhole mixed composite fracturing fluid within the downhole mixed composite fracturing fluid within the subterranean formation.

7. The method as defined in claim 1, further comprising:

adding to the aqueous fracturing fluid a selected amount of one or more additives from a group comprising chemical additives, gelling agents, alcohols, salts, fluid loss additives, and encapsulated additives; and

selectively varying the selected amount of the one or more of additives added to the aqueous fracturing fluid in response to selectively varying one or more of the first injection flow rate, the second injection flow rate and the third injection flow rate.

8. The method as defined in claim 1, further comprising:

adding a cross-linkable gelling agent to at least one of the carbon dioxide, the nitrogen and the aqueous fracturing fluid; and

adding a cross-linking agent to another of the carbon dioxide, the nitrogen, and the aqueous fracturing fluid such that the cross-linkable gelling agent and the cross-linking agent mix downhole in the casing bore in the composite fracturing fluid and cross-link at least a portion of the cross-linkable gelling agent.

9. A method of hydraulically fracturing a subterranean formation penetrated by a wellbore, at least a portion of the wellbore including a tubing string having a tubing bore and a casing string, the casing string and tubing string forming a casing annulus, a portion of the well bore not including the tubing string therein forming a casing bore, the method comprising:

injecting an aqueous fracturing fluid down one of the casing annulus and the tubing bore at a first injection flow rate;

simultaneously injecting an energized fluid down the other of the casing annulus and the tubing bore at a second 
injection flow rate;

combining the energized fluid and the aqueous fracturing fluid in the casing bore to form a first downhole mixed composite fracturing fluid having a first mixed fluid composition;

injecting the first downhole mixed composite fracturing fluid from the casing bore into the subterranean formation at a hydraulic pressure adequate to fracture the formation; and

selectively varying one or more of the first injection flow rate and the second injection flow rate to modify in real time the first mixed fluid composition of the first downhole mixed composite fracturing fluid to form a second downhole mixed composite fracturing fluid.

10. The method as defined in claim 9, further comprising:

adding a solid material proppant to the aqueous fracturing fluid to form a proppant laden downhole mixed composite fracturing fluid having a second mixed fluid composition; and

thereafter injecting the proppant laden downhole mixed composite fracturing fluid from the casing bore into the subterranean formation at hydraulic pressures sufficient to hydraulically fracture the formation.

11. The method as defined in claim 10, wherein a quantity of proppant in the composite fracturing fluid is adjusted in real-time by varying at least one of the first injection flow rate and the second injection flow rate.

12. The method as defined in claim 10, further comprising:

selectively varying one or more of the first injection flow rate and the second injection flow rate to modify in real time the second mixed fluid composition.

13. The method as defined in claim 10, further comprising:

monitoring in real time within the well bore a location in the formation of at least one radioactive tracer provided in at least a portion of one or more of the downhole mixed composite fracturing fluid and the proppant laden downhole mixed composite fracturing fluid by monitoring radioactive emissions from the at least one radioactive tracer; and

varying at least one of the first injection flow rate and the second injection flow rate in response to the monitored radioactive emissions.

14. The method as defined in claim 9, wherein the energized fluid further comprises:

at least one of carbon dioxide and nitrogen.

15. The method as defined in claim 9, further comprising:

while selectively varying one or more of the first injection flow rate and the second injection flow rate, increasing a viscosity of the second downhole mixed composite fracturing fluid as compared to the first downhole mixed composite fracturing fluid and cause viscous inter-fingering of the second downhole mixed 
composite fracturing fluid within the first downhole mixed composite fracturing fluid, within the subterranean formation.

16. The method as defined in claim 9, further comprising:

adding a gelling agent to one of the aqueous fracturing fluid and the energized fluid; and

adding a cross-linking agent to the other of the aqueous fracturing fluid and the energized fluid, such that the gelling agent and the cross-linking agent mix downhole in the casing bore.

17. A method of hydraulically fracturing a subterranean formation penetrated by a wellbore, at least a portion of the wellbore including a tubing string having a tubing bore and a casing string, the casing string and tubing string forming a casing annulus, a portion of the well bore not including the tubing string therein forming a casing bore, the method comprising:

injecting a first aqueous fracturing fluid including a cross-linkable gelling agent down one of the casing annulus and tubing at a first injection rate;

injecting a second aqueous fracturing fluid including a gel cross-linking agent down the other of the casing annulus and the tubing at a second injection rate;

combining the first aqueous fracturing fluid and the second aqueous fracturing fluid in the casing bore to form a downhole mixed composite fracturing fluid having a first mixed fluid composition;

injecting the downhole mixed composite fracturing fluid from the casing bore into the subterranean formation at pressures sufficient to hydraulically fracture the formation; and

selectively varying one or more of the first injection flow rate and the second injection flow rate to modify in real time the first mixed fluid composition of the downhole mixed composite fracturing fluid.

18. The method as defined in claim 17 , further comprising:

adding a solid material proppant to one or more of the first aqueous fracturing fluid and the second aqueous fracturing fluid to form a proppant laden downhole mixed composite fracturing fluid having a second mixed fluid composition; and

thereafter injecting the proppant laden downhole mixed composite fracturing fluid from the casing bore into the subterranean formation at pressures sufficient to hydraulically fracture the formation.

19. The method as defined in claim 18 , further comprising:

varying at least one of the first injection flow rate and the second injection flow rate to selectively modify in real time at least one of a physical property and a chemical property of at least one of the first mixed fluid composition and the second mixed fluid composition.

20. The method as defined in claim 19, wherein selectively adjusting in real time at least one of a physical property and a chemical property further comprises: 
selectively varying a viscosity physical property to cause viscous inter-fingering of fluids in the subterranean formation.

21. The method as defined in claim 18, wherein a quantity of proppant in the proppant laden downhole mixed composite fracturing fluid is selectively adjusted in real time by varying at least one of the first injection flow rate and the second injection flow rate.

22. The method as defined in claim 17 , further comprising:

monitoring in real time within the well bore a location in the formation of at least one radioactive tracer provided in at least a portion of one or more of the downhole mixed composite fracturing fluid and the proppant laden downhole mixed composite fracturing fluid by monitoring radioactive emissions from the at least one radioactive tracer; and

varying at least one of the first injection flow rate and the second injection flow rate in response to the monitored radioactive emissions.

23. The method as defined in claim 17 , further comprising:

injecting an energizing fluid comprising one or more of carbon dioxide and nitrogen with one or more of the first aqueous fracturing fluid and the second aqueous fracturing fluid.

\section{Description}

\section{ORIGIN OF THE INVENTION}

\section{Field of the invention}

This invention relates to hydraulic fracturing in petroleum and natural gas reservoirs, and more particularly to real-time modification thereof by downhole mixing of fracturing components.

\section{Background of the Invention}

A typical reservoir stimulation process involves hydraulic fracturing of the reservoir formation and proppant placement therein. The fracturing fluid and proppant are typically mixed in pressurized containers at the surface of the well site location. This surface-mixed composite fracturing fluid is generally comprised of an aqueous fracturing fluid, proppant, various chemical additives, including gel polymers, and often energizing components such as carbon dioxide (CO2) and nitrogen (N2). After adequate surface mixing, the composite fracturing fluid is pumped via high-pressure lines through the wellhead and down the wellbore, whereupon ideally the fluid passes into the reservoir formation and induces fractures. Successful reservoir stimulation fracturing procedures typically increase petroleum fluid and gas movement from the fractured reservoir rock into the wellbore, thereby enhancing ultimate recovery.

Reservoir stimulation procedures are capital intensive. Implementation difficulties arise with many known 
stimulation methods due to various problems, including limitations associated with surface mixing of the stimulation fluid. Typically, a viscous, surface-mixed composite stimulation fluid is injected at pressures adequate to create and propagate fractures in the reservoir. The pressures required to pump such stimulation treatments are relatively high, particularly during injection of the gelled, thickened fluids that may be used to propel proppant into the fractures. These pumping pressures often will increase during the treatment process to an excessive limit, whereupon the operator promptly and prematurely terminates the treatment. Otherwise, serious problems may result, including rupture of surface equipment or wellbore casing and tubulars.

Excessive treating pressures may also occur abruptly during the stimulation fracturing process as a result of premature screenout. Such screenouts are a common problem known in industry that may occur during a fracturing treatment when the rate of stimulation fluid leakoff into the reservoir formation exceeds the rate in which fluid is pumped down the wellbore, thus causing the proppant to compact within the fracture, and into the wellbore. This problem of premature screenout is discussed in U.S. Pat. No. 5,595,245, which is hereby incorporated by reference.

When premature screenout is observed during a fracturing treatment, the operator may elect to reduce the proppant quantity, density, or concentration of proppant per volume of fluid, in order to prevent the occurrence of the screenout. However, when the reduction in proppant concentration is made at the surface, a significant amount of time typically passes before the pumped fluid with altered proppant concentration actually reaches the formation.

A potential problem associated with surface-blended composite fluids is that inhibitors are required to prevent viscous gelling of the stimulation fluid prior to pumping downhole. Highly viscous gels are typically desirable for effective transport of proppant, however, if viscous gelling occurs too early, such as in the tanks and flowlines, or before the fluid is pumped down the well, the efficiency of the overall stimulation job may be compromised due to higher pressures and lower pump rates. To avoid premature gelling, various known chemical inhibitors that include encapsulated or chemically coated inhibitors may be mixed into the composite fluid mixture at the surface to provide a time delayed gelling of the composite fracturing fluid. In addition, other known additives may be incorporated at the surface in an attempt to predictably control the rate of gelling, such as inhibitors to time-delay activation of cross linked polymer gels, which prevents premature gelling of the composite fracturing fluid. A serious shortcoming of this surface-mixed approach, however, is either gelling too early, or too late as evidenced by inadequate gel quality, which frequently results in poor proppant transport and premature screenout.

Typically in many wells the fracturing treatments are terminated prematurely, or reduced in size due to excessive pumping pressures that result from surface mixed and pumped fracturing treatments. In older wells, the premature gelling of the composite fracturing fluid creates a significant potential of exceeding the rated casing or tubing burst pressure. In a 12,000 feet well, for instance, surface wellhead treating pressures often exceed 10,000 psi. whereas bottomhole treating pressures at the reservoir formation depth are significantly higher due to the combination of hydrostatic weight of the composite fracturing fluid (in wellbore) plus surface pumping pressures and friction pressure. The resultant bottomhole treating pressures, if excessive, may crush or fracture proppants in the fracture, which is undesirable due to the release of fines, fracture closure and overall formation damage.

Higher treating pressures are detrimental in terms of requiring lower pump rates, and thereby often alter the overall fracturing stimulation design at the well site. Frequently, the volumetric amount of composite fracturing fluid and proppant that are pumped is lower than desired due to restricted pump rates. Typically higher pumping 
pressures result in larger horsepower requirements, the usage of more pump engines, and higher cost. Reservoir stimulation fracturing is a capital intensive process, and ineffective reservoir stimulation treatments result in a significant loss of both expended capital and the potential recovery of hydrocarbon reserves.

A typical industry fracturing procedure may commence with mixing of the composite fracturing fluid in storage tanks located on the surface at the well site. The composite fracturing is typically comprised of aqueous gelled fluid, chemical additives and energizers such as $\mathrm{N} 2$ and $\mathrm{CO} 2$. After mixing, the composite fracturing fluid is pumped via high-pressure lines through the wellhead, down the wellbore and injected into the induced formation fractures. The pumping procedure is typically initiated with the pumping of a pad stage, which is typically fluid without proppant, followed by various stages of fluid containing proppant, and upon termination of the proppant-laden fracturing stage by pumping of the flush stage, which is generally fluid without proppant. This aforementioned sequence occurs when the treatment is pumped as designed, and in the absence of problems including excessive treating pressures and premature screenout.

Another typical industry stimulation technique is known in industry as hydraulic notching or "hydrajetting", whereby fluid is injected downhole to cut slots into the production casing or openhole reservoir formation, and thereby induce fractures in the reservoir formation. Conversely this technique may also be used in openhole and horizontal well stimulation procedures. This known stimulation procedure comprises pumping limited proppant concentration during fracturing through casing or in openhole formation, whereby fluid with proppant is typically pumped via tubing through Tungsten jet nozzles that are located at the distal end of the tubing. In the hydrajetting process, mixing of the tubing and annular flow-streams occurs adjacent to the reservoir formation as generally similar fluids are simultaneously pumped down casing. This procedure is typically limited to stimulation applications involving smaller fractures where proppant concentrations are relatively low (usually less than 5 pounds per gallon) in comparison to most typical sand-fracturing techniques, and furthermore the total amounts of proppant that are placed in the fracture are relatively low.

The hydrajetting process may include pumping of different fluids simultaneously down annulus and tubing, in terms of one fluid type consisting of proppant. This process is flexible in allowing different fluid types including acid to be used, but is also relatively expensive in comparison to typical known fracturing techniques. Annular rates are adjusted to maintain fracturing pressures as fractures are generated by the hydrajet fracturing process. A limitation in the use of this system occurs, however, as jets may become eroded during the fracturing injection process, in addition turbulent flow patterns may disperse proppant in the near-wellbore fractures. The proppant washout may be due to a Bernoulli affect, whereby the annular pressures are lower than the fracture tip pressures.

\section{SUMMARY OF THE INVENTION}

In accordance with the present invention, there is provided a real-time hydraulic fracturing process in which substantial quantities of both nitrogen and carbon dioxide may be separately injected, via the tubing string and casing annulus, to form, in the downhole region of the wellbore, a composite fracturing fluid that may include an aqueous-based fluid, a proppant, $\mathrm{N} 2$ and $\mathrm{CO} 2$ energizers and various other chemical components. This inventive process may be used to stimulate reservoirs in vertical and horizontal wells, and in openhole and cased wells. The inventive system may also be used for enhanced reservoir recovery procedures to remediate depleted reservoirs in mature fields, via short phase tertiary $\mathrm{CO} 2$ injection.

Downhole-blending proximal to the reservoir zone is accomplished by dual injection of different fluids through 
coiled or conventional tubing and casing annulus. A composite fracturing fluid is thus created downhole prior to injection into the reservoir formation fracture. The aqueous based fracturing fluid may be incorporated into either or both of the gases at the surface and may include proppant and other chemical components, which form the composite fracturing fluid upon mixing downhole. This downhole-mixed fracturing fluid is blended downhole to avoid excessive friction pressures and then injected at a desirable thickened viscosity and at a pressure sufficient to implement hydraulic fracturing of the selected reservoir interval.

Known additives, including thickening agents, may be incorporated into the base-fluid to increase fluid viscosity, to improve proppant suspension, leak-off and related rheological properties. Carbon dioxide may be provided in liquid phase via the tubing and nitrogen may be provided in gaseous phase via the casing, or conversely the carbon dioxide may be injected down the casing and nitrogen down the tubing. Thorough mixing of the propping agent with the composite stimulation fluid preferably occurs immediately above or adjacent to the reservoir interval where the induced reservoir fracture or fractures are propagated. The procedure of downhole-mixing may be accomplished concurrent with tracer monitoring, in real-time, as described in our U.S. Pat. No. 5,635,712 (Scott-Smith), which is hereby incorporated by reference.

In the event of a premature screenout, an operator typically immediately ceases pumping proppant down the casing annulus and the fracturing job is terminated prematurely, or conversely the operator might attempt to abruptly increase the rate of pumping in an often futile endeavor to create new fracture growth, or increase the existing fracture width. However, these known techniques typically do not always yield satisfactory results, and may even worsen the problem in terms of screening out, fracturing out of the desired reservoir zone, or ruining the wellbore casing due to excessive pressures and resultant pipe rupture.

A variety of problems are avoided in real-time by this method of downhole mixing, which provides the ability to substantially instantaneously modify stimulation treatment by rapid changes in pump rate, fluid rheology and proppant concentrations. This inventive system typically minimizes friction pressures and thus provides lower treating pressures and higher pumping and injection rates. Downhole mixing facilitates true real-time modification of the fracture treatment, and provides near instantaneous alteration of fluid viscosity and proppant concentrations at the reservoir, as is described further below.

\section{BRIEF DESCRIPTION OF THE DRAWINGS}

FIG. 1 is a schematic cross-sectional representation of a fracturing procedure showing the various stages involved.

FIG. 2 illustrates a typical downhole-blended real-time hydraulic fracturing operation illustrating surface facilities and pump trucks, with simultaneous injection of different components down tubing and casing to form a composite fracturing fluid in the downhole region.

FIGS. 3-5 illustrate variations and/or consecutive progression of downhole-mixed well stimulation procedures with pumping of various components down tubing and casing annulus.

\section{DETAILED DESCRIPTION OF THE PREFERRED EMBODIMENTS}

FIG. 1 illustrates various stages during a typical fracturing treatment sequence, whereby fracturing fluid is blended downhole and pumped in pre-pad (10), pad (20), proppant (30) and flush (40) stages. As indicated, aqueous fluid, which might also be comprised of gelled hydrocarbons, is pumped down casing (50) while the 
tubing 60) is a "dead string", which provides the operator measurement of bottomhole treating pressure during the fracturing process. Alternately, the surface-mixed composite fracturing fluid may be pumped down tubing (60), or the same fluid may be pumped simultaneously down both tubing and casing. The composite fracturing fluid is generally comprised of various additives, including gel, proppant, or energizers including CO2 and Nitrogen, which are mixed at the surface prior to pumping down the well for injection into the formation to induce fracturing.

In the inventive embodiment illustrated in FIG. 2, the novel process of employing carbon dioxide, nitrogen, aqueous fluid and other chemical additives in accordance with downhole mixing may be understood by reference to the hydraulic fracturing operation as indicated. Aqueous gel (65) with Nitrogen (70), and liquid $\mathrm{CO} 2$ (80) are pumped concurrently down casing (50) and tubing (60) respectively, at constant or variable ratios during successive treatment stages. The liquid CO2 (80) is pumped from storage tank via high pressure line (110) by pump (120) through the wellhead (130) and down the tubing (60) during simultaneous pumping of gelled fluid (140) with methanol and Nitrogen (70) down the cased wellbore (50). Downhole-mixing forms a composite fracturing fluid (150) above or adjacent to perforations (160), which are located proximal to the desired reservoir (170) objective. A hydraulically induced fracture (180), shown in cross-sectional view, contains the composite fracturing fluid (150). Alternate arrangements of surface equipment, for mixing various components at the surface, are possible. The fluid content of the composite fracturing fluid is typically subject to water leakoff into reservoir formation (170). Different combinations of known fluid components and chemical additives may be mixed downhole to reduce the fluid leakoff.

FIGS. 3-5 show a downhole-mixed fracturing procedure sequentially as the treatment progresses through various stages. FIG. 3 shows the initial fracturing fluid (190) pumped via casing into the reservoir zone of the well adjacent to the reservoir formation to be fractured. Fracture initiation is established (as evidenced by formation breakdown pressure) whereupon the formation mechanically fails and one or more fractures (180) are formed during injection of this initial pad stage (190) into the reservoir formation. The initiation of a fracture or fractures in the formation usually is accompanied by a relatively abrupt and substantial decrease in bottomhole treating pressure, which is monitored by operator at the well site surface.

FIG. 4 shows the subsequent mixing downhole of composite fracturing fluid (150), as fluid component (200) is pumped via casing and $\mathrm{CO} 2$ (80) is concurrently pumped down tubing. In this embodiment, the pump rates may be varied for the purpose of achieving desirable fracture growth and proppant placement within the reservoir zone. In addition, fluid rheology may be selectively altered, in real-time, as a result of modification of relative pump rates at surface of tubing versus casing. Both the composite fracturing fluid rheology and proppant concentration may be modified essentially at or near the perforations, in real-time. This system facilitates prompt changes in proppant concentration, which is particularly important under certain circumstances such as when attempting to avoid premature screenout of the fracturing treatment. Avoidance of premature screenout may be achieved by prompt reduction of proppant concentration in the downhole region by increasing the rate of clean (i.e. without proppant) fluid or energizer ( $\mathrm{CO} 2$, Nitrogen) relative to the proppant-laden aqueous fluid. Avoidance of screenout in real-time thus may be achieved by increasing the relative rate of clean fluid, or energizer, from tubing, with respect to sand-laden fluid that is pumped via casing. Both tubing and casing flowstreams may separately or together include chemical additives that are specifically applied to further minimize the rate of fluid leakoff into the formation, which contributes toward the occurrence of premature screenout.

FIG. 5 illustrates the pumping of a proppant-laden slurry (210) including energizers (such as N2) down casing concurrent with the pumping of $\mathrm{CO} 2$ (80) down tubing. Real-time modification of the composite fracturing 
fluid (150) and to another composite fracturing fluid (160), including varied proppant concentration, may be facilitated by adjusting the injection rates of tubing and casing relative to each other. The net composition of the composite fracturing fluid (i.e. rheologic properties) and proppant concentrations may be altered as desired by altering the rates that the tubing and casing components are pumped. For example, the composite fracturing fluid may be adjusted, in real-time, from a ratio of 40\% CO2-30\% N2-30\% aqueous fluid slurry (with proppant) to a $80 \% \mathrm{CO} 2-15 \% \mathrm{~N} 2-15 \%$ aqueous fluid slurry by increasing the volumetric rate of $\mathrm{CO} 2$ pumped down tubing. Although the pumping equipment is located at the surface, like a syringe the effectuated increase in tubing pump rate is immediately evidenced at the bottom of the wellbore and results in a real-time change in the composite fracturing fluid entering the formation. As a result, the proppant concentration is changed in realtime by the increased ration of clean fluid or $\mathrm{CO} 2$ relative to the proppant-laden slurry. The rate of change may be further accentuated by simultaneously decreasing the casing annular pump rate while increasing the tubing pump rate, such as might be indicated by premature screenout and the need to radically reduce proppant entry into the formation.

According to the present invention, each of at least two fluids used for fracturing formations penetrated by subterranean wellbores may be pumped down respective tubular conduits, simultaneously, to mix and interact in a downhole portion of the wellbore forming a composite fracturing fluid therein, which is then pumped into the formation/reservoir.

The pump rate of fluid in one or both tubular conduits may be selectively and individually varied to effect changes in composition of the composite fluid, substantially in real time to exert improved control over the fracturing process, including the quality, physical and chemical properties of the composite fluid entering the formation. Proppant transport qualities thereby may also be modified substantially in real time. Other benefits may also be realized, such as reduced friction losses, reduced hydraulic horsepower requirements, and improved pump rate limits over the restrictions that may be imposed by wellbore tubular sizes.

By providing separate conduits for respective separate fluid compositions at the surface, composite downhole fracturing fluid combinations that might otherwise have been impractical if mixed at the surface, may be permissible. For example, a first fracturing fluid phase including carbon dioxide may be pumped down the tubing, while a second fluid phase including nitrogen, gelled aqueous fluid and proppant may be pumped down the casing annulus. The first and second fluid phases may combine and mix downhole in the casing to form a composite fracturing fluid that might otherwise have exhibited too much friction loss to have been pumped from the surface as a composite fracturing fluid. In like fashion, cross-linking may be performed downhole in the casing without relying on "delayed" cross-linking techniques that result from predictable fluid pH changes. For example, a borate gel may be incorporated concurrently with $\mathrm{CO} 2$, which if mixed at the surface the $\mathrm{CO} 2$ would act as an efficient breaker of the borate gel crosslinking action.

Often, a desirable embodiment may of downhole-mixing may be used to create viscous inter-fingering of $\mathrm{CO} 2$ or other gaseous phases within the aqueous pad fluid that is present in the formation fracture. Although mixing along the interfaces of the different density phases may also occur, the vertical separation of discrete phases in the fractures, due to fluid phase or density variations, may likely result. Under some circumstances this discrete separation of different phase types in the fracture is desirable, such as to avoid placement of proppant in water-productive zones, or to avoid fracturing into gas-oil, gas-water, or water-oil contacts in the reservoir.

The term "aqueous fracturing fluid" as used herein may be defined broadly to encompass any liquid fracturing fluid, including water based fluids, alcohol based fluids, or crude oil based fluids, or any combination thereof. 
Energizers such as carbon dioxide and/or nitrogen may be pumped down one or both tubular conduits, individually or in combination with one of the aqueous fracturing fluids or some portion thereof. "Carbon dioxide" may include liquid carbon dioxide, and may also include carbon dioxide miscibly dissolved in a liquid, or foamed with another liquid as either the continuous or discontinuous phase. "Nitrogen" may include also include nitrogen or a nitrogen containing compound alone, or mixed with, foamed, or partially dissolved in a liquid, or without a liquid. Carbon dioxide in the liquid phase is highly soluble in water, however, nitrogen is relatively insoluble in water, even at comparatively high pressures commonly encountered at the bottom of a well.

Water based fracturing fluids may include fresh water based fluids, sea water based fluids, or brine solutions, and may further include added salt compounds, such as $\mathrm{KCl}$ and $\mathrm{NaCl}$. Alcohol based fracturing fluids may include aliphatic alcohols such as methanol, ethanol, isopropyl alcohol, tertiary butyl alcohol and/or other alcohol based compounds. Oil based fracturing fluids may also be included within the term "aqueous fracturing fluid" as used herein, and may include "live oil," "dead oil," "crude oil," "refined oil," condensate, or other hydrocarbon based fluids. Any combination of gelling, thickening, cross-linking, or other known fracturing fluid additives may be included in any of the above fracturing fluids.

2

Another embodiment comprises pumping aqueous fluid with proppant and other chemicals additives, including methanol or other alcohols, down casing while concurrently pumping $\mathrm{CO}_{2}$ down tubing. Or conversely $\mathrm{CO}_{2}$ may be mixed with Nitrogen, or $100 \%$ Nitrogen may be pumped down tubing for admixture with fluid components. As a result of pumping this configured embodiment, the composite fracturing fluid that is comprised of aqueous fluid, methanol, proppant and $\mathrm{CO}_{2}$ is pumped at substantially reduced pumping pressures relative to the current industry practice of first mixing said components in surface tanks prior to pumping down the wellbore. The advantages of this downhole-blended embodiment include lower treating pressures, lower horsepower pumping requirements, and lower overall costs related to the procedure. In addition, this procedure provides means for adjusting both fluid rheology and proppant concentration in real-time. Said adjustments in rheology include changes in gel strength, viscosity, and gel-breaker quality.

In another inventive embodiment, downhole-mixing may be achieved by the pumping of aqueous gel crosslinking agents down tubing or casing, while concurrently pumping gel crosslinking activators and other chemical additives down casing or tubing, respectively, to result in a more precisely controlled crosslinking of the composite gelled fracturing fluid. Cross-linking agents may be blended in the downhole region with polymeric thickening agents comprising borate gels or multivalent metal ions such as titanium, zirconium, chromium, antinomy, iron, and aluminum. The cross-linking agents and polymer combinations include, but are not limited to mixing guar and its derivatives as a polymer with a cross-linking agent of titanium, zirconium or borate; a polymer composition of cellulose and its derivatives cross-linked with titanium or zirconium; acrylamide methyl propane sulfonic acid copolymer cross-linked with zirconium.

Downhole mixing provides efficient turbulent dispersion of both carbon dioxide and nitrogen in the gelled aqueous fluid. This downhole-blending procedure may also be conducted with either or both Nitrogen and $\mathrm{CO} 2$ added into the downhole-mixed composite fracturing fluid, in various stages or the entirety of the fracturing treatment. Or conversely, Nitrogen and CO2 energizers may not be required in some circumstances, such as when adequate reservoir pressures are present to assure a relatively prompt flowback and cleanup of the composite fracturing fluid. C0.sub.2 may be supplied as a liquid at about -10.degree. F. to 10.degree. F. and at a pressure of about 250 to $350 \mathrm{psig}$. Nitrogen may be supplied as a gas, normally at ambient temperature of from about 65.degree. F. to 115.degree. F. The composite fracturing fluid may be at a pressure at the wellhead that is typically within the range of from less than 1,000 to more than $12,000 \mathrm{psig}$. 
In addition, various chemical additives may be mixed downhole to modify gel quality. Downhole-mixed hydrophyllic gels may be employed, which swell when water molecules are encountered. As a result, gels may be primed by downhole-mixing with activators and known chemicals to create freshly reactive hydrophilic gels that drastically increase fluid viscosity whenever water-productive zones are encountered, thus plugging or sealing fractures as a result. Thus, as fracture propagation out of a desired reservoir interval occurs, hydrophilic molecules may be created in the downhole region for binding water molecules and concurrently sealing the fracture to minimize unwanted water production.

Enhanced gels may be created by downhole blending. Chemical mixtures that are created or activated by downhole-mixing may be employed to modify relative fluid or gas flow characteristics of the reservoir rock. Relative reservoir permeability may be modified by application of known chemicals and known activators that are mixed in the downhole region, particularly those that react relatively rapidly, as compared to current practices of pumping surface-admixed gels that often may be compositionally unstable. CO2and nitrogen may be included in this process. $\mathrm{CO} 2$, nitrogen and various other known additives including surfactants may be mixed downhole to alter wetting properties and interfacial tension angles between the hydrocarbon and reservoir rock. The gel rheology and ratios of nitrogen and carbon dioxide to the aqueous fracturing fluid may be altered at various stages of operation, in real-time, if a sudden unanticipated change in bottomhole treating pressure occurs, or as early premature screenout is evidenced or suspected.

During the fracturing process, a typical propping agent, such as Ottawa frac sand or ceramic particles, may be employed in concentrations ranging from less than 0.5 to 15 pounds of sand per gallon of fracturing fluid. Viscosifying agents may be employed to increase the viscosity of the aqueous solution and to increase the propping agent concentration, which may be progressively increased, or decreased as desired during the fracturing treatment.

Subsequent to the injection of the propping agent into the fracture, it may be desirable to complete the operation with the injection of a wellbore flushing fluid that is absent propping agent. This flushing fluid functions to displace previously injected propping agent into the fracture and reduces the accumulation of undesirable quantities of propping agent within the well proper. The flush stage may also include various chemical additives including resin activators and inhibitors.

At the conclusion of the displacement of proppant-containing fluid, the fracturing operation normally is concluded by the injection of a flushing fluid to displace the propping agent into the fracture. The well may then be shut in for a period of time to allow the injected fluid to reach or approach a state of equilibrium, with both the carbon dioxide and the nitrogen in the gaseous phase. After the well is placed on production by flowing the well back, via a positive pressure gradient extending from the reservoir to the surface via the wellbore, the comingled nitrogen and carbon dioxide function to effectively displace the aqueous fracturing fluid from the formation. This provides a clean-up process at the conclusion of the fracturing operation since both nitrogen and carbon dioxide dispel fluids from the formation.

By using the inventive process of downhole mixing, the operator has more options when faced with premature screenout. These options include simultaneously increasing pump rate down the tubing with circulation of the casing fluid into pits, or conversely, the operator may elect to dilute proppant concentration entering the reservoir in real-time by increasing the pump rate of clean fluid relative to the pump rate of proppant-containing slurry, thus decreasing the amount of proppant per volume of composite fracturing fluid entering the formation. This inventive downhole mixing method may also be used to avoid screenout by increasing the effective 
admixture of additives for the purpose of minimizing fluid loss to the formation, in real-time.

As a practical matter, the addition of polymeric thickening agents, and other additives incorporated therewith, hydration of the aqueous fluid to form the initial gel, and the addition of propping agent may be accomplished under ambient surface temperature and pressure conditions. Injection of these components via tubing and casing is accomplished to induce downhole-mixing adjacent to the reservoir.

A cross-linking agent may be injected separately (down tubing) from the other chemical components (down casing), so that initiation of cross-linking reaction occurs downhole immediately prior to injection of the composite fluid into the reservoir. This facilitates avoidance of a premature increase in viscosity of the fracturing fluid as it travels downhole in the casing or tubing, which often occurs with surface-mixed composite fluids. Premature viscosification of the fracturing fluid creates excessive treating pressures as a result of friction loss. During a fracturing procedure, increased fluid friction requires increasing hydraulic horsepower, which increases costs and often restricts overall pump injection rates.

The composition of the aqueous phase of the fracturing fluid may include polymer gelling agents, surfactants, clay stabilizers, foaming agents, and potassium salt. Methanol may be added to the fracturing fluid in those cases where the formation contains substantial quantities of clay minerals. It is often times desirable to add from about 10-20 volume percent methanol to the fracturing fluid in such circumstances. Polymeric thickening agents are useful in the formation of a stable fracturing fluid. Examples of known thickening gelling agents may contain one or more of the following functional groups: hydroxyl, carboxyl, sulfate, sulfonate, amino or amide. Polysaccharides and polysaccharide derivatives may be used, including guar gum, derivatized guar, cellulose and its derivatives, xanthan gum and starch. In addition, the gelling agents may also be synthetic polymers, copolymers and terpolymers. Cross-linking agents may be combined with the solution of polymeric thickening agents including multivalent metal ions such as titanium, zirconium, chromium, antinomy, iron, and aluminum. The cross-linking agents and polymers may be combined as desired via downhole mixing. These combinations include but are not limited to (1) admixing guar and its derivatives as a polymer with a cross-linking agent of titanium, zirconium or borate; (2) polymer composition of cellulose and its derivatives cross-linked with titanium or zirconium; (3) acrylamide methyl propane sulfonic acid copolymer cross-linked with zirconium. The amount of thickening agent utilized depends upon the desired viscosity of the aqueous phase and the amount of aqueous phase mixed downhole in relation to the energized phase, that is, the liquid carbon dioxide and nitrogen phase. As the amount of liquid carbon dioxide and nitrogen increases, the amount of aqueous phase will commonly be $20 \%$ to $50 \%$. Reservoir injection rates and composition of the component fracturing fluid will vary in the downhole region as a function of modification of relative pump rates for tubing and casing. This allows the operator to control proppant concentration and relative gas-fluid ratios as the composite fluid enters the reservoir fracture, all of which may be varied or kept constant, in real-time as desired by the operator.

Additives and water are typically admixed into an aqueous fracturing fluid at the surface throughout the fracturing operation, or the gelled fluid may be formulated before the operation and kept in surface storage tanks until needed. Various additives as described may then be blended into the water in the tanks, or via downhole blending, depending on the operator's objective intent. After additives are thoroughly blended with the water, the water becomes "gelled", whereby the thickened aqueous fluid may be transferred from the storage tanks to a blender. Proppant, when required, may be added via mixing tub attached to the blender at a selected rate to achieve the required concentration, in pounds per gallon of liquid, to obtain the desired downhole concentration. The treating fluid or gel-proppant slurry may be transferred by transfer pumps at a low pressure, usually about 100-300 psi, to high pressure generally greater than 500 psi, by tri-plex pumps. The tri-plex pumps inject the separate fracturing components into the treating lines that are connected directly at the 
wellhead to tubing and casing, at a desired rate and pressure adequate to hydraulically fracture the formation.

Carbon dioxide may preferably be introduced in the liquid phase down the bore of the tubing string, whereas typically nitrogen is pumped in the gaseous phase down the casing (annular area between the tubing string and the casing). The agitation and turbulent shearing associated with downhole blending provides adequate mixing of the carbon dioxide and nitrogen within the aqueous fluid mixture. Downhole mixing according to this invention also provides uniform blending of carbon dioxide and nitrogen with the aqueous phase and forms a composite fracturing fluid with desirable proppant-carrying properties.

The aqueous base fluid phase may contain various chemical additives routinely used by those skilled in the art, including gelled hydrocarbons, and may be pumped separate for mixing downhole. For example, polymers, cross-linking agents, catalysts, and surfactants, and the aqueous phase may also contain one or more biocides, surface tension reducing non-emulsifying surfactants, clay control agents, salts, fluid loss additives, buffers, gel breakers, iron control agents, paraffin inhibitors and alcohols. Various of these components may be injected separately via tubing and casing for admixture in the downhole region of the well.

Having described specific embodiments of the present invention, it will be understood that other modifications thereof may now be apparent to those skilled in the art. The invention is thus intended to cover all such modifications of downhole blended fracturing, which are within the scope of the appended claims. 


\title{
SPE 77676
}

\author{
Real-Time Downhole-Mixed Stimulation Fracturing Process \\ George Scott III, Realtimezone, Gary Covatch, NETL, and Art Carrasco, Halliburton
}

\begin{abstract}
Copyright 2002, Society of Petroleum Engineers Inc.
This paper was prepared for presentation at the SPE Annual Technical Conference and Exhibition held in San Antonio, Texas, 29 September-2 October 2002.

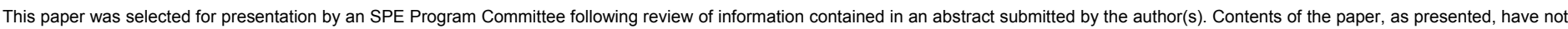

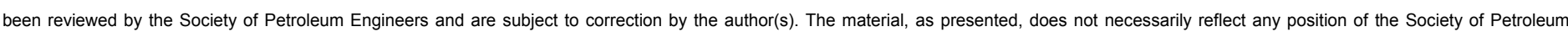

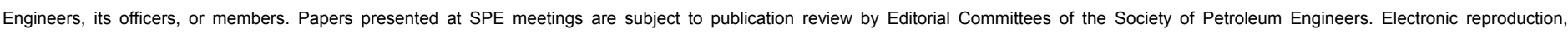

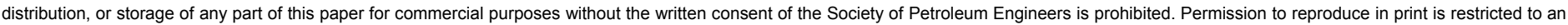

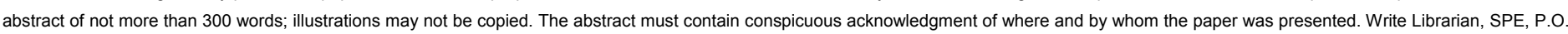
Box 833836, Richardson, TX 75083-3836, U.S.A., fax 01-972-952-9435.
\end{abstract}

\section{Abstract}

A field-tested reservoir fracturing process comprised of carbon dioxide $\left(\mathrm{CO}_{2}\right)$, fluid, and proppant was mixed downhole to generate a composite fracturing fluid that was modified in real time at the reservoir. This fracturing system provides numerous advantages over present industry fracturing practices, including reduced friction pressures and lower pumping-treatment pressures. In addition, this downholemixing process improves wellsite safety, reduces equipment horsepower requirements, and enables the operator to alter treatment mixture and proppant concentrations concurrent with the reservoir fracturing stimulation procedure in real time.

The first field application of this fracturing process was performed in September 2000 in an abandoned 12,300-ft Morrow gas well in the Sand Point field of Eddy County, New Mexico. The fracturing treatment consisted of methanol gel with 7,000 $\mathrm{lb}$ of bauxite proppant that was pumped down the annulus and blended above the perforations with 40 tons of liquid $\mathrm{CO}_{2}$, which was pumped down the tubing. A postfracture tracer log showed that the treatment was placed in the objective reservoir as designed. Initial production from the well was approximately $250 \mathrm{Mcfd}$.

A common problem during fracturing is high surface treating pressures, which may prevent the pumping of fracturing treatments in their entirety. Typically, surfacemixed fracturing treatments are pumped at pressures that may exceed 10,000 psi. At these higher pressures, the stimulation treatment is aborted prematurely unless extra-strength tubulars are deployed. However, during the first downhole-mixed treatment, tubing pressures were observed at less than 6,000 psi, and casing pressures at less than 5,000 psi.

A second field application of the downhole-mixed fracturing system was performed in March 2002 in a stripper 
oil well (Delaware formation). Gelled lease oil, proppant, and $\mathrm{CO}_{2}$ were mixed downhole in an attempt to improve production from this well while avoiding fracturing out of zone. The detailed results from both test wells are presented in this paper.

\section{Introduction}

A real-time enhanced reservoir fracturing technology is currently under development and final field-testing. ${ }^{1,2}$ This real-time stimulation process involves the mixing of separate fluid types in the downhole region of the well to create a composite fracturing fluid that can be modified on the fly to alter various rheological properties and proppant concentrations. Additionally, different fracturing-fluid phases can be created to induce real-time viscosity interfingering in the reservoir fracture(s). ${ }^{3}$ The downhole mixing process can be used concurrently with real-time fracture monitoring ${ }^{4}$ to enable the operator to change fracture propagation and improve resultant fracture geometries, proppant concentration, and proppant placement. ${ }^{1,2}$ In addition, downhole mixing has remediation applications.

Enhanced fluid emulsion systems may also be created by mixing surfactants, gases, fluids, and other chemical additives. Real-time mixed fluid emulsions could possibly be modified to induce fluid viscosity variations and interfingering of stimulation fluids and proppant within the reservoir fractures. The interfacial tension between fluids and reservoir rock may be selectively altered by downhole-mixed activation of chemical additives.

Further modeling and field-testing should help assure that this technology, and variations of the real-time dual-fluid stimulation system, will be developed for more widespread application by the industry. ${ }^{5}$ This testing should demonstrate the feasibility of pumping a downhole-mixed nitrogen $\left(\mathrm{N}_{2}\right)$ and $\mathrm{CO}_{2}$ composite fluid. The proposed well-test objective should prove that a $\mathrm{CO}_{2}-\mathrm{N}_{2}$-gel stimulation system can be pumped effectively while fracturing-fluid properties and proppant concentration are controlled in real time. The well tests may be augmented with real-time tracer diagnostic monitoring - $\mathrm{a}$ technology that is currently under development. Post-fracture tracer logging will be conducted for data comparisons in well tests.

\section{Description, Application, and Advantages}

Theoretically, downhole blending of gas $\left(\mathrm{CO}_{2}\right.$ and $\left.\mathrm{N}_{2}\right)$ and gel should result in a composite stimulation fluid that is comparable in efficiency and proppant transport to a conventional foam treatment that is mixed at the surface. However, downhole blending of the composite fluid provides numerous advantages, including less fluid-pipe friction, lower pressures, and reduced cost. On preliminary test wells, tracers should be used to tag the proppant and fluid stages to determine if more efficient reservoir proppant placement is possible with this proposed system. ${ }^{6}$ Additional well testing is planned to determine whether downhole-blended fracturing processes using $\mathrm{N}_{2}$ gas mixed downhole with $\mathrm{CO}_{2}$ and gelled fluids are technically feasible. If successful, the proposed $\mathrm{N}_{2-}$ $\mathrm{CO}_{2}$-gel systems may alleviate some stimulation problems that the petroleum industry currently experiences.

Process. Downhole mixing is accomplished by precision blending of gases, proppant, and fluids in the downhole region of the well, above or near the reservoir objective. This approach can eliminate the need for the greater pumping horsepower that is typically required under the higher friction pressures characteristic of viscous, surface-mixed stimulation fluids. Significantly lowered treating pressures are often critical to successfully fracturing reservoirs, particularly in deep wells that have a lot of friction pressure associated with pumping down small tubulars. This is especially true when treating wells in which old or weak tubulars are present, making pumping down the casing at high pressures or rates not an option. When mechanical or safety issues are considered, downhole mixing is often preferable to conventional stimulation methods. 
Downhole blending occurs when different fluids for admixture are dual-injected through coiled or conventional tubing and the casing annulus near the reservoir zone. Thus, a composite fracturing fluid is created downhole before injection into the reservoir formation fracture. The aqueousbased fracturing fluid may be incorporated into either or both of the gases at the surface and may include proppant and other chemical components, which form the composite fracturing fluid upon mixing downhole. First, this fracturing fluid is blended downhole to avoid excessive friction pressures, and then it is injected at a viscosity and pressure sufficient to implement hydraulic fracturing of the selected reservoir interval.

Additives, including gelling agents, may be incorporated into the base fluid to increase fluid viscosity and improve proppant suspension, leak-off, and related rheological properties. $\mathrm{CO}_{2}$ may be provided in liquid phase through the tubing, and $\mathrm{N}_{2}$ may be provided in gaseous phase through the casing, or the $\mathrm{CO}_{2}$ may be injected down the casing and $\mathrm{N}_{2}$ down the tubing. The propping agent should be thoroughly mixed with the composite stimulation fluid immediately above or adjacent to the reservoir interval where the induced reservoir fracture or fractures are propagated.

Advantages. Current reservoir stimulation procedures are generally inflexible; however, downhole mixing allows easy adjustment of treatment design while the fracture treatment is mixed downhole. Real-time fracturing control can minimize and potentially eliminate some common industry stimulation problems, including fluid-reservoir skin damage, excessive treating pressures, fracturing out of zone, and excessive water production. These problems can result in a significant loss of hydrocarbon reserves and severe economic loss to the operator. The proposed dual-fluid completion system test could provide enhanced stimulation processes for real-time modification of fluid rheology and proppant concentration, maximizing proppant placement while minimizing the common stimulation problems that can result in poor recovery efficiency. With downhole mixing, stimulation treatments can be instantaneously modified with rapid changes in pump rate, fluid rheology, and proppant concentrations. This flexible system typically minimizes friction pressures, providing lower treating pressures and higher pumping and injection rates.

Altering the rates at which the tubing and casing components are pumped can control the net composition of the composite fracturing fluid (i.e., rheologic properties) and proppant concentrations. For example, increasing the volumetric rate of $\mathrm{CO}_{2}$ pumped down the tubing can change the composite fracturing fluid, in real time, from a ratio of $40 \% \mathrm{CO}_{2}$ to $30 \% \mathrm{~N}_{2}$ to $30 \%$ aqueous fluid slurry (with proppant) to a $70 \% \mathrm{CO}_{2}$ to $15 \% \mathrm{~N}_{2}$ to $15 \%$ aqueous fluid slurry. Although the pumping equipment is located at the surface, the effectuated increase in tubing pump rate is immediately evidenced at the bottom of the wellbore and results in a real-time change in the composite fracturing fluid entering the formation. The rate of change may be further accentuated by simultaneously decreasing the casing annular pump rate while increasing the tubing pump rate, such as might be indicated by premature screenout and the need to radically reduce proppant entry into the formation.

Existing completion systems use surface-mixing of the composite fracturing fluid. The pressures required to pump such stimulation treatments are relatively high, particularly during the injection of gelled, thickened fluids required to carry proppant into the fractures. Often, these pressures may become excessive during the treatment process, and the operator must prematurely terminate the treatment before serious equipment damage or safety problems occur.

Another significant problem associated with surfaceblended composite fluids is that inhibitors are required to delay the crosslinking of the stimulation fluid before pumping downhole. Typically crosslinking occurs in the lower region of the wellbore before the fluid enters the performations. Highly viscous gels effectively transport the proppant, but if premature viscous gelling occurs in the tanks and flowlines or before the fluid is pumped down the well, higher pressures and 
lower pump rates can occur, compromising the efficiency of the overall stimulation job. Inhibitors and other additives can be mixed into the composite fluid mixture at the surface to provide a controlled, time-delayed gelling of the composite fracturing fluid. A serious shortcoming of this surface-mixed approach, however, is that inadequate gel quality frequently results in poor proppant transport and premature screenout. Downhole blending of fluids can reduce or eliminate this timing factor, assuring a more uniform gel quality. Otherwise impractical composite downhole fracturing-fluid combinations mixed at the surface may be permissible if a conduit for each fluid composition is provided at the surface. For example, a first fracturing-fluid phase including $\mathrm{CO}_{2}$ may be pumped down the tubing, while a second fluid phase including $\mathrm{N}_{2}$, gelled aqueous fluid, and proppant may be pumped down the casing annulus. The first and second fluid phases can mix downhole in the casing and form a composite fracturing fluid that otherwise might have exhibited too much viscosity to be pumped from the surface as a composite fracturing fluid. Similarly, crosslinking may be performed downhole in the casing without relying on delayed crosslinking techniques that result from less predictable fluid $\mathrm{pH}$ changes.

Although mixing along the interfaces of the different density phases may occur, the vertical separation of discrete phases in the fractures, due to fluid phase or density variations, may likely result. Under some circumstances, this discrete separation of phase types in the fracture is desirable because separation can help avoid placement of proppant in water-productive zones, and fracturing into gas-oil, gas-water, or water-oil contacts in the reservoir. ${ }^{7}$

In fact, sometimes treatments can damage, rather than enhance, reservoir productivity, and reserves and revenues are lost. An unsuccessful treatment may result from incompatible fluids and poor fluid recovery after fracturing because lowpermeability reservoirs do not effectively flow back fluids from the matrix pores effectively (compared to higherpermeability reservoirs). ${ }^{8}$ This lack of efficient fluid cleanup is typically evidenced by fluid-mineral interaction (skin damage) and substantially reduced fluid entry into the wellbore. Unsuccessful fracturing treatments may also result from inefficient placement of sand proppant in the induced reservoir fracture or excessive water production from fracturing vertically away from the reservoir interval (and into waterbearing strata). This type of treating out of zone can result in economic losses and lost petroleum reserves. In addition, extensive well stimulation costs are wasted.

Although a well that has been fractured out of zone can sometimes be saved, remedial efforts are often extensive, risky, and costly. The proposed dual-fluid fracturing system tests can provide a valuable solution to these problems by providing simpler and more effective methods that may include a more focused method of fracturing. In many fields, this system can control fracture propagation during stimulation and help prevent chronic problems and minimize water production that can occur when a well is fractured out of zone.

In addition to fracture stimulation procedures, downhole mixing also has remediation applications. For example, precision blending of sodium silicate polymers and chemical activators can help efficiently induce plugging of waterproductive zones (before, after, or during fracturing). Another example is resin-coated proppants that may be selectively activated downhole. ${ }^{9}$ Additional testing is needed to develop a full spectrum of real-time and dual-fluid stimulation and remediation processes. ${ }^{10}$

In other cases, fracturing treatments are terminated prematurely or reduced in size because the excessive pumping pressures create the potential of exceeding the rated casing or tubing burst pressure. In deeper wells, surface wellhead treating pressures can approach 10,000 psi or higher. Conversely, bottomhole treating pressures at the reservoir formation depth are significantly higher due to the combination of the hydrostatic weight of the composite fracturing fluid (in wellbore) and surface pumping pressures and friction pressure. The resultant bottomhole treating pressures, if excessive, may crush or fracture proppants in the fracture, which can cause fines release, fracture closure, and 
formation damage. Higher treating pressures also require lower pump rates, which can alter the overall fracturing stimulation design at the wellsite. Frequently, job designs are dictated by pump rates. Typically, higher pumping pressures result in larger horsepower requirements, the usage of more pump engines, and higher cost. Downhole mixing can help alleviate these common industry problems.

\section{Field Tests}

The first dual-fluid fracturing treatment was blended downhole at approximately $12,300 \mathrm{ft}$ in a deep gas reservoir (Pennsylvanian Morrow formation). Fig. 1 illustrates the pumping pressures of tubing and casing during the experimental fracturing treatment. Pressures were 4,000 psi lower than average treating pressures for this depth.

The post-fracture tracer log (Fig. 2) shows that the dualfluid fracturing treatment successfully placed 7,000 $\mathrm{lb}$ of proppant into the induced reservoir fracture at $12,300 \mathrm{ft}$. A commercial gas producer (approximately 5,000 Mcf per month) was created from a wellbore that was scheduled for plugging.

The second dual-fluid fracturing treatment was downholeblended at 4,900 $\mathrm{ft}$ in a shallow oil reservoir (Permian Delaware formation). Other oil wells in this field area are typically characterized by excessive water production resulting from treatment out of zone. The pressure treatment chart (Fig. 3) shows that the reservoir interval in this test well was successfully stimulated by placement of 7,470 $\mathrm{lb}$ of proppant at $4,900 \mathrm{ft}$, with screenout selectively induced in the fracture near the end of the treatment. Oil production from this well increased $300 \%$ with no increase in water production.

The tracer survey $\log$ (Fig. 4) and produced oil cut confirmed that adjacent water intervals were not treated. The measured minimum fracture height was less than $40 \mathrm{ft}$ and the majority of the treatment was concentrated within $25 \mathrm{ft}$ of the reservoir section. This low fracture height is especially significant because relatively low fracture gradients usually occur in the general field area. Most shallow wells in this field area exhibit fracture heights in the range of 100 to $300 \mathrm{ft}$. The field wells that are treated out of zone are typically characterized by excessive water production.

Completed field tests have proven that the process is technically feasible. Further testing will also help finalize algorithms related to dual-fluid field pumping procedures. The scientific significance includes the fact that friction pressures between fluids, casing, and tubing are reduced. Further field confirmation of the dynamic downhole-mixing processes should aid in determining applications for this method and result in the widespread adaptation over current stimulation methods.

\section{Conclusions}

Downhole-mixed fracturing technology provides an enhanced stimulation process that can directly improve the recovery of petroleum reserves. Advantages of downhole mixing include economy, efficiency, and safety.

The costs of downhole mixing are comparatively less than normal industry fracturing procedures because downhole mixing requires lower friction pressures, which translates into reduced fuel and pump horsepower requirements. The lower observed treating pressures that result help prevent accidents and equipment damage.

The downhole-mixing process can provide well operators the ability to instantly modify fracturing treatment mixture and proppant concentrations at the reservoir, resulting in increased reservoir recovery efficiency. Downhole mixing can be used to blend different fracturing fluid phases and induce viscosity interfingering in the reservoir fracture. This real-time enhanced process facilitates control of fracture height and allows the stimulation treatment and proppant placement to be concentrated in the desired reservoir interval, directly resulting in the increased recovery of petroleum reserves.

The process of downhole-mixed fracturing is simpler, safer and lower cost than typical surface-mixed stimulation treatments. In addition, this enhanced stimulation procedure provides the well operator a real-time process to control 
proppant concentration and placement in the reservoir, enhancing the recovery of petroleum reserves. Ultimately, the widespread application of this enhanced stimulation technology could result in more efficient and more substantial recovery of natural gas and oil.

Introduction of the dual-fluid system to the industry requires additional field-testing to demonstrate more applications in various types of reservoirs, including low-

\section{Acknowledgements}

The authors thank Realtimezone, NETL, and Halliburton for their support and permission to publish this paper.

\section{References}

1. Eberhard, M.J. et al:: "Precise Fracture Initiation Using Dynamic Fluid Movement Allows Effective Fracture Development in Deviated Wellbores," paper SPE 62889 presented at the 2000 SPE Annual Technical Conference and Exhibition, Dallas, Texas, 1-4 October.

2. Scott, G.L. III and Carrasco, A.: "Delaware Sandstone Reservoir Completions and Real-Time Monitoring of Hydraulic Fractures," paper presented at the 1995 Symposium of the Roswell Geological Society, July.

3. Harris, P.C. and Walters, H.: "Real-Time Control of LowPolymer Fracturing Fluids," paper SPE 63238 presented at the 2000 SPE Annual Technical Meeting, Dallas, Texas, 1-4 October.

4. Scott, G. and Smith, H.: "Method for Monitoring the Hydraulic Fracturing of a Subterranean Formation," U.S. Patent No. $5,635,712(1995)$.

5. Wright, C.A. et al.: "Real-Time Fracture Mapping from the 'Live' Treatment Well,' paper SPE 71648 presented at the 2001 SPE Annual Technical Conference and Exhibition, New Orleans, Louisiana, 30 September-3 October. permeability gas zones. Dissemination of test result data to the petroleum industry is crucial to the development of a more full-spectrum dual-fluid fracturing system. The innovative dual-fluid fracturing system is simple to use at the wellsite, helping to prevent potential barriers that may result from misunderstanding or misuse by wellsite operators and service providers.

6. Urbancic, S.C. et al.: "Evaluating fracture stimulations with microseismicity," World Oil (May 2002) 85-86.

7. Deeg, W.F.J.: "The Effect of Frac-Fluid Density on Hydraulic Fracture Growth Direction and Width," paper SPE 39427 presented at the 1998 International Symposium on Formation Damage Control, Lafayette, Louisiana, 18-19 February.

8. Dusterhoft, R. et al.: "Controlled Viscosity Reduction and Increased Fracture Conductivity Using a High-Temperature Breaker System," paper SPE 39896 presented at the 1998 International Petroleum Conference and Exhibition of Mexico, Villahermosa, Mexico, 3-5 March.

9. Scott, G.: "Systems of Injecting Phenolic Resin Activator during Subsurface Fracture Stimulation for Enhanced Oil Recovery," U.S. Patent 5,595,245 (1995).

10. Weaver, J.D. et al.: "Application of Surface Modification Agent in Wells with High Flow Rates," paper SPE presented at the 1999 Latin American and Caribbean Petroleum Engineering Conference, Caracas, Venezuela, 21-23 April. 


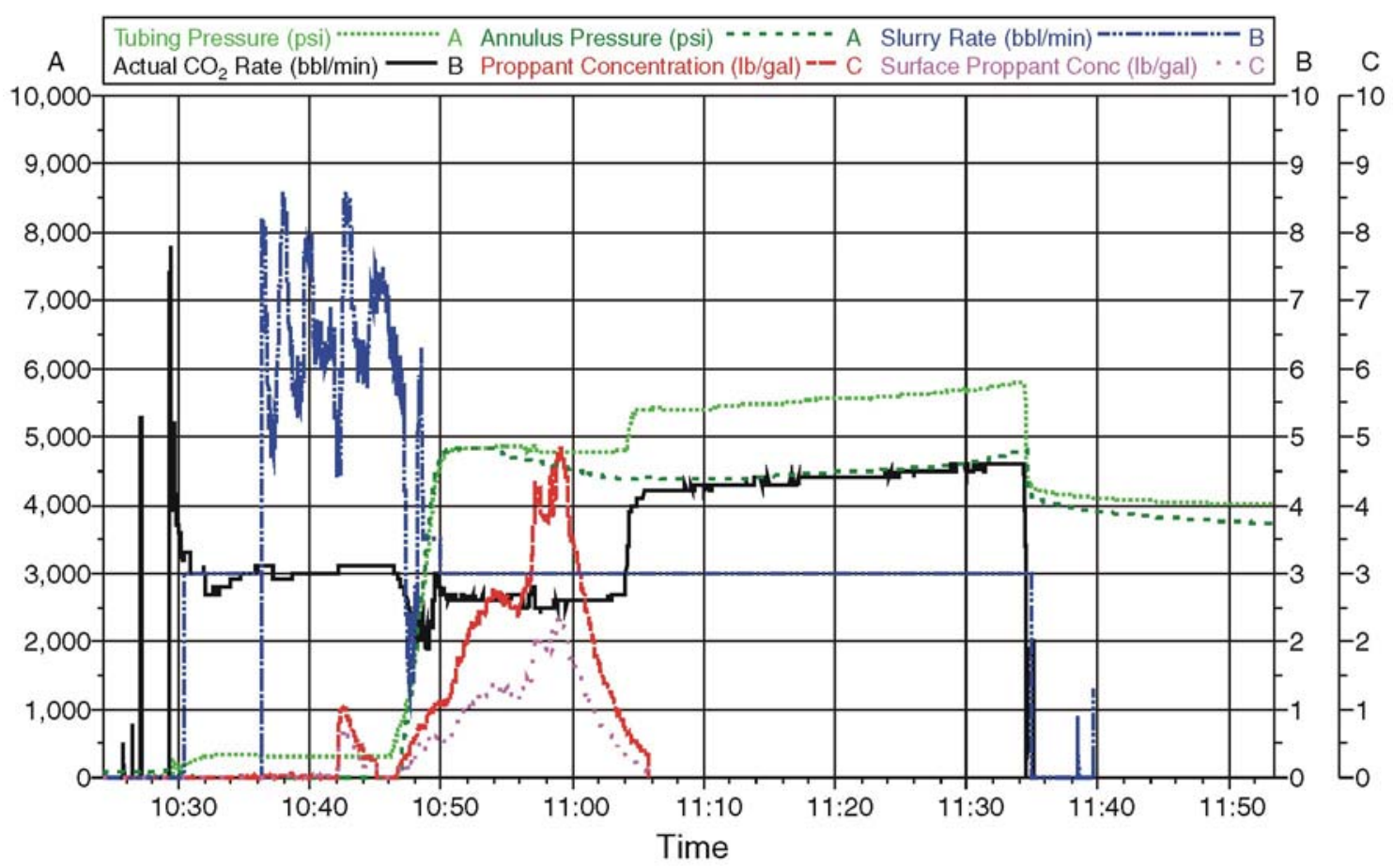

Fig. 1-Pressure treatment chart for Job 1.

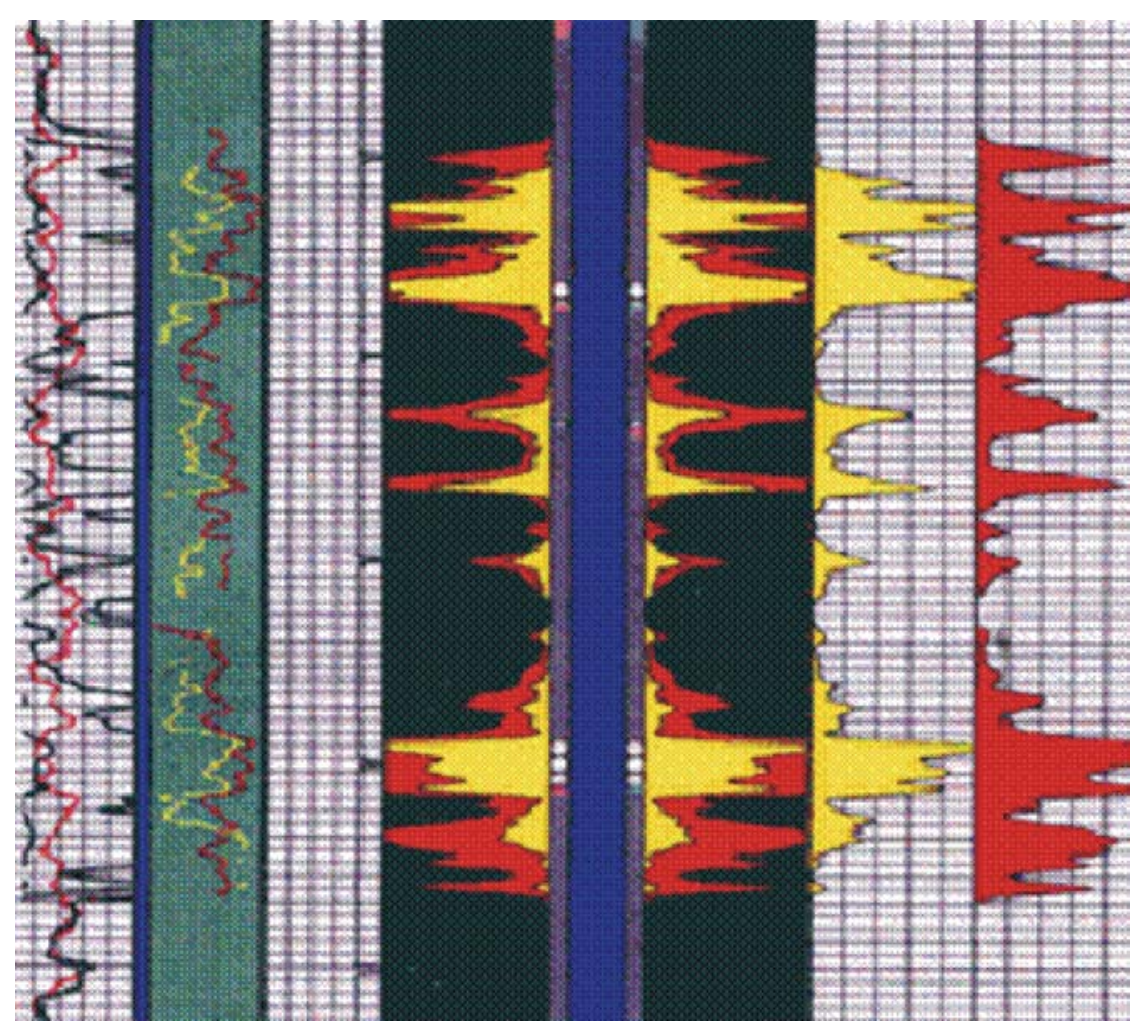

Fig. 2-Dual-isotope tracer log (yellow = tubing tag, red = casing tag). 


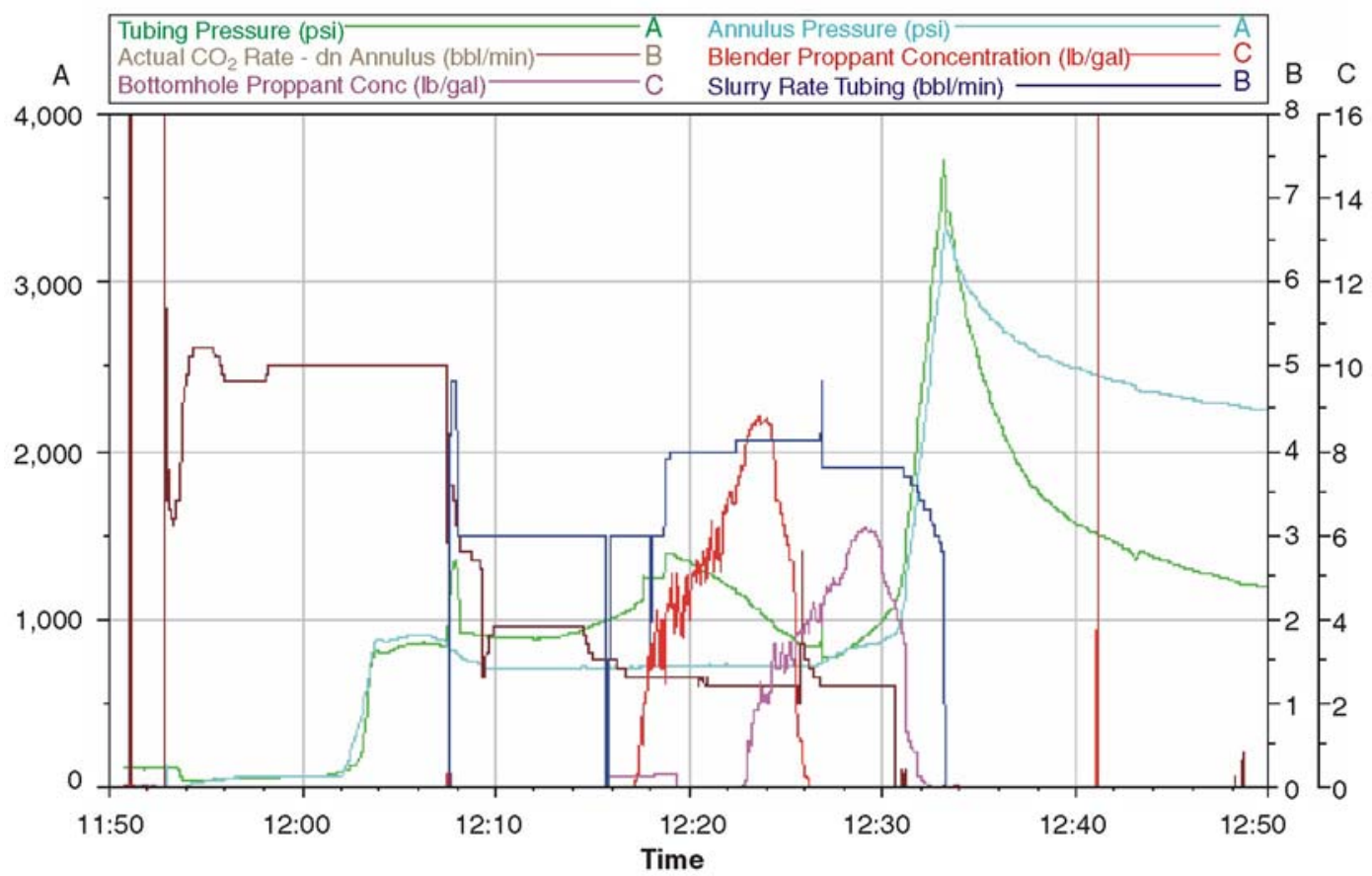

Fig. 3-Pressure treatment chart for Job 2.
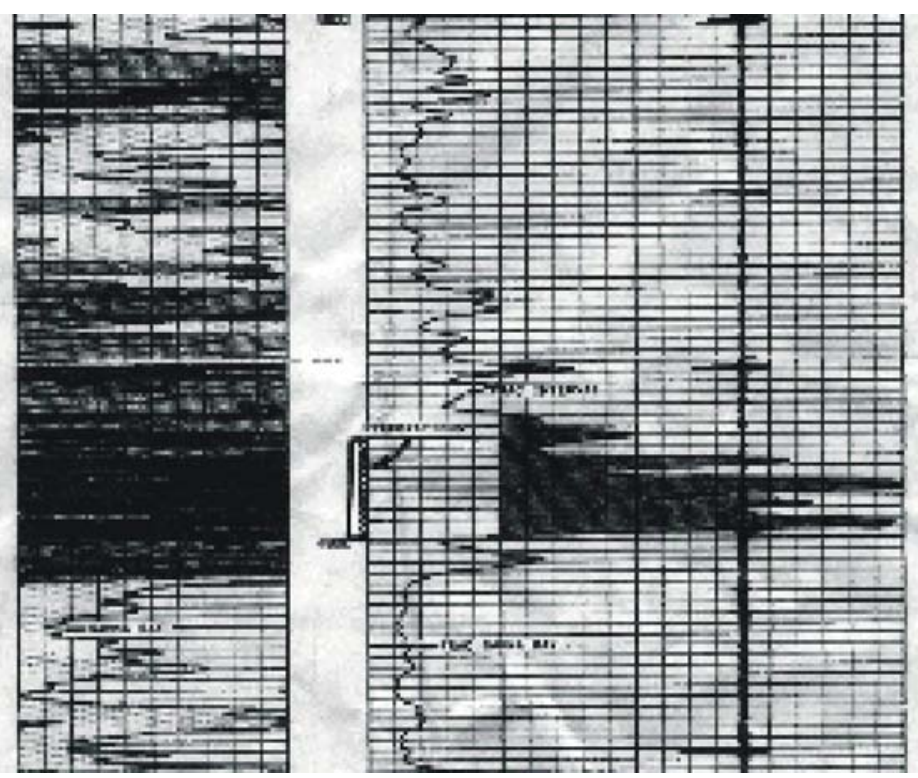

Fig. 4-Tracer survey log for Job 2. 